\title{
Integrating BIM and New Rules of Measurement for Embodied energy and $\mathrm{CO}_{2}$
} assessment

*Corresponding author's email: fabanda@brookes.ac.uk

1

\section{Abstract}

Embodied energy/ $\mathrm{CO}_{2}$ computational models can help decision-makers choose appropriate technologies, building materials, systems and processes that minimize impacts on the 5 environment. While existing models have been great in the assessment process, they often 6 suffer from two main weaknesses. Firstly, models exist in silos and only fit for computing 7 individual material type at any one time. Secondly, computational results obtained from most models are not aligned to standard measurement methods used in practice. In this study, a 9 system that can automate the computation of embodied energy $/ \mathrm{CO}_{2}$ of buildings and aligns 20 the results to the UK New Rules of Measurement (NRM) has been proposed. The developed 1 system was tested using case study houses with known dimensions. It allows the 22 simultaneous determination of embodied energy $/ \mathrm{CO}_{2}$ and cost and aligns the results to the 23 UK NRM concepts. This is useful for simultaneously determining the environmental impact 4 of building components and their corresponding costs.

6 Key words: Building performance, Computation models, Construction industry, Embodied 7 energy, New rules of measurement

\section{Introduction}

0 The political pressure on governments and organisations in the world to address the adverse 1 effects of climate change has been mounting for quite some time now. The shares of the 32 effects of climate change are different with different sectors of the economy. In the UK, the 
construction industry accounts for $47 \%$ of greenhouse emissions (BIS, 2010). Thus, the construction industry is responsible for a significant share of emissions into the atmosphere. No wonder reducing embodied energy and carbon dioxide $\left(\mathrm{CO}_{2}\right)$ of buildings has increasingly become a very hot topic amongst governments and/or environmental organisations. Embodied energy can be defined as the quantity of energy used during the lifecycle of materials, upstream or downstream of the development of a building (construction, renovation or refurbishment) (Gaspar and Santos, 2015). It thus includes the energy used for the: extraction, transport, processing of raw materials, manufacturing of building materials and components, various processes of the on-site assembly, storage, performance, deconstruction and disposal of materials (Sartori and Hestnes, 2007; Dixit et al., 2010). The extraction, processing, manufacture, transportation, assembly and use of a product utilizes energy and induces harmful emissions, including $\mathrm{CO}_{2}$ and other greenhouse gases (Häkkinen et al., 2015). The induced $\mathrm{CO}_{2}$ is what is referred to as embodied $\mathrm{CO}_{2}$. Embodied carbon is often confused with embodied $\mathrm{CO}_{2}$. In this study, we strictly stick to embodied $\mathrm{CO}_{2}$, and embodied carbon can be computed from embodied $\mathrm{CO}_{2}$ using molar mass relationships of the constituent elements. On the other hand, operational energy is the energy consumed in running or conditioning (e.g. heat, cool, ventilate and light) the interior spaces of a building and to power equipment and services (Abanda et al., 2014). Thus, operational $\mathrm{CO}_{2}$ is the $\mathrm{CO}_{2}$ emission induced from the operational energy. The UK government has long set a legally binding $80 \%$ reduction in $\mathrm{CO}_{2}$ emissions compared to 1990 levels by 2050 as part of the 2008 Climate Change Act (HMSO, 2008). The most recent UK construction strategy report requires the built environment to cut emissions by $50 \%$ by 2025 (The HM Government, 2013) to the 1990 levels. The targets currently require net zero operational carbon emissions for all domestic buildings after 2016 and net zero operational carbon emissions for all new non-domestic buildings after 2019 (HM Government, 2011). Such ambitious stringent targets require every source of emissions to be minimized or cut if possible.

In the past, focus has been on the operational energy of buildings with the assumption or belief that embodied energy was too small (Pacheco-Torgal et al., 2013; Cabeza et al., 2014; Dixit et al., 2012). Pacheco-Torgal et al. (2013) reported that embodied energy represents between $10-15 \%$ of operational energy. Cabeza et al. (2014) reported that embodied energy constituted $10-20 \%$ of life cycle energy of a building. Some studies have reported figures as 
low as $2 \%$. For example, Sartori and Hestnes (2007) reported that embodied energy could account for $2-38 \%$ of total life cycle energy of a conventional building and $9-46 \%$ for a lowenergy building. In addition to embodied energy, the production of building materials (e.g. extraction, transportation and manufacturing processes) releases $\mathrm{CO}_{2}$ mainly due to the use of fuel or electricity. Thormark (2006) reported that embodied energy in traditional buildings can be reduced by approximately $10-15 \%$ through proper selection of building materials with low environmental impacts. González and Navarro (2006) estimated that the selection of building materials with low impacts can reduce $\mathrm{CO}_{2}$ emissions by up to $30 \%$. In the UK, Sturgies (2010) predicts the proportion of embodied carbon to increase from $30 \%$ to $95 \%$ while the operational carbon will reduce to $5 \%$ from $70 \%$ for a domestic dwelling over the coming 7-10 years with improved legislation. As the operational energy use decreases, embodied energy use will occupy a greater portion of the building life cycle. The effective implementation of policies such as the Energy Performance Building Directive could see significant reduction in operational energy while embodied energy could increase to almost $40 \%$ of the operational energy in the near future (Cabeza et al., 2013). Therefore embodied energy and $\mathrm{CO}_{2}$ are quite important in environmental building assessment.

Consequently, it is not surprising that recent interest in embodied energy and $\mathrm{CO}_{2}$ research has grown to very significant levels. The scale of research in this area can be noted in Dixit et al. (2010) and Abanda et al. (2013a). Dixit et al. (2010) conducted an extensive literature review and reported 10 parameters that influence the quality of embodied energy results. Abanda et al. (2013a) reviewed 11 main models consisting of 23 equations used for computing embodied energy from at least 20 peer-reviewed studies. Based on a review of the different studies in Dixit et al. (2010), Abanda et al. (2013a) and other recent literature (see the section 2) it emerged that a system that automatically compute embodied energy and $\mathrm{CO}_{2}$ for buildings, in compliance with well-established standard measurement methods is needed. The issue of automatic computation of quantities has been a long standing challenge and widely acknowledged in the literature. One of the early studies that highlighted the need for automated computation of quantities from Computer-Aided-Design (CAD) systems was the work of Neuberg and Rank (2002: pp. 26). In the study, the authors quoted: "the main problem is that most of the simulation tools and CAD are not linked together. The time consuming manual data input and the additional expenditure to the normal planning work is economically not bearable, particularly if different scenarios have to be compared". The 
preceding two sentences underpins the major differences between CAD and BIM systems and served as some of the major reasons for adopting BIM in this study. Firstly, BIM offers the opportunity to superpose multidisciplinary information within a powerful federated project model (Ilhan and Yaman, 2016). Secondly, the ability to simulate, assess and compare different construction parameters (e.g. embodied energy, operational energy, cost, etc.) of construction project virtually before contractors begin to construct it in reality is a key strength of BIM (Vernikos, 2012). Furthermore, Kim and Anderson (2013) argued that virtual BIM models can be visually checked to ensure modelling accuracy. This real-time virtual and fast way of simulating and exploring various options of construction projects and their impacts makes BIM one of the most powerful systems in supporting decision-making processes. Although compliance or alignment of computation results with standard measurement methods has been an issue for some time, it received interest with the increasing capability and popularity of BIM. Recent studies (e.g. Olatunji et al. (2010), Zhiliang et al. (2011), Olatunji and Sher (2014), Ma et al. (2013), Monteiro and Martins (2013)) argued the need to align material/component quantities with standard measurement methods.

The aim of this study is to investigate and develop a system that can automate the computation of embodied energy and $\mathrm{CO}_{2}$ of buildings and aligns the results to New Rules of Measurement, one of the UK leading standards of construction measurement methods. This aim is achieved through the following research objectives:

i. to develop an algorithm that can be implemented in any BIM software system for the assessment of embodied energy/ $/ \mathrm{CO}_{2}$ and cost of a building project;

ii. automate the extraction of quantities and embodied energy $/ \mathrm{CO}_{2}$ and cost from a BIM software to the proposed system;

iii. align the computational results of the embodied energy and $\mathrm{CO}_{2}$ to the UK New Rules of Measurement and hence cost data for building cost estimation;

test the system using selected case study buildings.

The remainder of this paper has been divided into 9 sections. In the second section, a review of other embodied energy and $\mathrm{CO}_{2}$ studies has been undertaken. This enabled the understanding of how embodied energy and $\mathrm{CO}_{2}$ has been computed in past. In the third 
section, a brief research method for this study is presented. In the fourth section, a detailed investigation into the importance of mathematical modelling and different types of mathematical models was undertaken. That led to the identification of the main mathematical models that served as the basis for the proposed system. In the fifth section, the approach used in digitising the UK New Rules of measurement that was used in mapping the computation of embodied energy and $\mathrm{CO}_{2}$ is presented. The development and implementation of the proposed system is discussed in the sixth section. An application based on a chosen house (a single ground floor, lounge, 2 bedrooms, 1 bathroom, a kitchen and a dining room) is examined in the seventh section. The challenges and how they were overcome are discussed in the eighth section. In the ninth section, a recapitulation and a discussion about the process and output from this paper are discussed. The paper is concluded in the tenth section by a way of a summary of what has been undertaken with perspectives of future studies.

\section{An overview of the scientific literature}

Since the publication of Abanda et al. (2013a) that reiterated the need for an automated system underpinned by an integrated mathematical model that can be used to compute embodied energy and $\mathrm{CO}_{2}$ also argued in Neuberg and Rank (2002), we sought to investigate progress made about embodied energy and $\mathrm{CO}_{2}$ computation. On reviewing studies since Abanda et al. (2013a), four major findings can be identified.

Firstly, many studies are still focusing on domain challenges that complicate computations processes. Some examples of domain problems are issues related to difficulties associated with boundary definitions of buildings and attribution of respective sources of energy (e.g. diesel, coal, biomass etc.) to the resulting embodied carbon (Kibwami and Tutesigensi, 2014). Takano et al. (2014) revealed that the numerical differences between database inventories are quite large with differences originating from multiple data elements. Davies et al. (2015) argued that embodied energy intensity data are represented in various inconsistent forms (i.e. weight per unit, weight of total, length, $\mathrm{Kg} / \mathrm{m}^{2}$ ) which are not easily transferable for computation; highlighting the need for further standardisation of units for environmental measurement. Secondly, case studies revealing share size of embodied energy and carbon have been quite common (Galán-Marín et al. 2015; Davies et al. 2015; Rauf and Crawford 2015; Gaspar and Santos 2015; Jang et al. 2015; Atmaca and Atmaca 2015). For example, 
165 Galán-Marín et al. (2015) conducted a study that compared the embodied energy of conventional load-bearing walls versus natural stabilized earth blocks. Thirdly, recent decision support tools have tapped into emerging BIM and Semantic Web to address key issues such as facilitating automatic extraction of data and improving intelligence have not adequately integrated embodied energy/ $\mathrm{CO}_{2}$ and construction cost. Hou et al. (2015) investigated how ontology and Semantic Web rules can be used in a knowledge-based system, to represent information about structural design and sustainability, and to facilitate decision-making in design process by recommending appropriate solutions for different use cases. A prototypical system named OntoSCS (Ontology for Sustainable Concrete Structure), including a Web Ontology Language (OWL) ontology as knowledge base and Semantic Web Rule Language (SWRL) providing reasoning mechanism was developed to offer optimised structural design solutions and selections of material suppliers. Embodied energy and $\mathrm{CO}_{2}$ are used in the system as indicators to evaluate sustainability of structure. Zhang and Issa (2013) conducted a study and demonstrated that the use of ontology provides a way to deal with the technical complexity of Industry Foundation Classes (IFC) models. Zhiliang et al. (2011) proposed an IFC -based model for construction estimation for tendering in China. The study by Zhiliang et al. (2011) was further extended by Ma et al. (2013) where algorithms for exporting and filtering IFC data to align with specifications and other constraints for cost estimation in China were developed. Fourthly, while Neuberg and Rank (2002) focused on sustainability, albeit without considering embodied energy and/or carbon, most studies are related to cost estimation (e.g. Olatunji et al. (2010), Zhiliang et al. (2011), Olatunji and Sher (2014), Ma et al. (2013)). So far, existing efforts to align standard measurement methods with cost data have been very limited. Ma et al. (2013) and Cheung et al. (2012) developed systems for the representation of cost information in alignment with the Chinese and UK standard measurement methods respectively. However, although Cheung et al. (2012)

190 focused on the UK NRM, it was based on early design stages where information about the 191 building project is scarce and thus less complex. Perhaps, partly because of the lack of BIM-

192 based systems for aligning quantities with standard measurement methods, the Royal

193 Institution of Chartered Surveyors recently funded a study to investigate how BIM can 194 support the UK New Rules of Measurement (NRM 1) (Wu et al., 2014). This study culminated in a proposed framework without any software for automatic extraction of cost data and alignment with NRM 1. 
While the aforementioned studies in the preceding paragraphs have further detailed the understanding of embodied energy and $\mathrm{CO}_{2}$ computation, there are still some challenges to be addressed. Isolated models are quite common and still being used in computing embodied energy and $\mathrm{CO}_{2}$ of buildings (Galán-Marín et al. 2015; Davies et al. 2015; Rauf and Crawford 2015; Gaspar and Santos 2015; Jang et al. 2015; Atmaca and Atmaca 2015). The much discussed need for a generalised model in Abanda et al. (2013a) has still not been addressed. Many models for the quantification of environmental emissions and construction project performance have evolved independently and still exist in isolation (Teng and $\mathrm{Wu}$ 2014; Abanda et al. 2014). While the OntoSCS in Hou et al. (2015) can be considered an automated process, it is important to note that the Semantic Web is still emerging and usability or presentation of results in user-friendly interfaces is still a challenge. Furthermore, OntoSCS system used Semantic Web Rule Langue (SWRL), and presented the results in SWRLTab, a rule-based development environment, not so user-friendly, especially to construction professionals. Finally, none of the studies aligned their computed results to any standard measurement methods, e.g. the UK New Rules of Measurement. It is important to adopt a standard way of outputting results to ensure consistency, verification, validation and comparison of results across different building components. Furthermore, by adopting existing standards of measurements such as the UK New Rules of Measurement used for cost estimation, it is possible to simultaneously determine the cost and environmental impacts of building components. For example, it will be possible to determine the cost of superstructure of a building as well as its environmental impact based on embodied energy. This study will address these shortcomings. Our proposed approach builds on Abanda et al. (2015), Nepal et al. (2013), Staub-French et al. (2003) to develop a system that extracts in an automatic fashion, quantities from one of the leading BIM software system, i.e. Revit and computes embodied energy and $\mathrm{CO}_{2}$ while aligning the results with the UK NRM 1. Abanda et al. (2015) argued for the need to integrate cost and environmental impact for simultaneous assessment, hence a component for cost estimation was also included in the proposed system. The system allows for the cost and environmental impacts (i.e. embodied energy and $\mathrm{CO}_{2}$ ) of building elements to be simultaneously determined.

\section{Research Methods}

229 The research framework proposed for this study is presented in Figure 1. The first part 
231 that underpin the proposed system. The exploration and adaption of the most relevant

232 mathematical models for computing embodied energy and $\mathrm{CO}_{2}$ is an important activity that

233 will be discussed in section 4 . The second part consists of digitising or developing NRM 1

234 ontology that depicts a structured NRM 1 work break down structure. One of the main

235 recommendations in ontology development is the consideration and re-use of existing

236 ontology if it exists (Noy and McGuinness, 2001; Gómez-Pérez et al., 2011). We reviewed

237 leading ontology libraries (Swoogle (http://swoogle.umbc.edu/) and Protégé ontology library

238 (http://protegewiki.stanford.edu/wiki/Protege_Ontology_Library) ) and existing literature

239 (Abanda et al. 2013b; Abanda et al. 2015; Grzybek et al 2014; Pauwels et al. 2016) for the

240 identification of potential standard measurement ontologies for re-use. Despite the fact that

241 many ontology libraries are rich in ontologies covering various disciplines, a specific

242 ontology that could be used or at least serve as a basis for the ontology of this study could not

243 be found. With regards to peer-reviewed literature, recent studies have focused on detailed

244 applications of ontologies in different built environment disciplines and applications. Abanda

245 et al. (2013b) and Grzybek et al. (2014) conducted extensive review about different

246 ontologies applications in the built environment. However, the studies did not reveal anything

247 related to standard measurement ontologies, talk less of NRM 1 ontology. Even the most

248 recent study by Pauwels et al. (2016) discussed ontology applications for product

249 manufacture, building energy performance, regulation compliance checking and geographical

250 and infrastructure. Only Abanda et al. (2015) provided initial concepts of NRM 1 ontology.

251 Therefore, in line with ontology development practice, the NRM 1 ontology in Abanda et al.

252 (2015) was enriched and used. The third part consists of detail implementation that leads to

253 the computation of embodied energy/ $/ \mathrm{CO}_{2}$ and cost and aligns them to NRM1. The results are

254 summarised and presented in a chart. The detail of part 3 of Figure 1 is covered in sections

255 six and seven.

256 


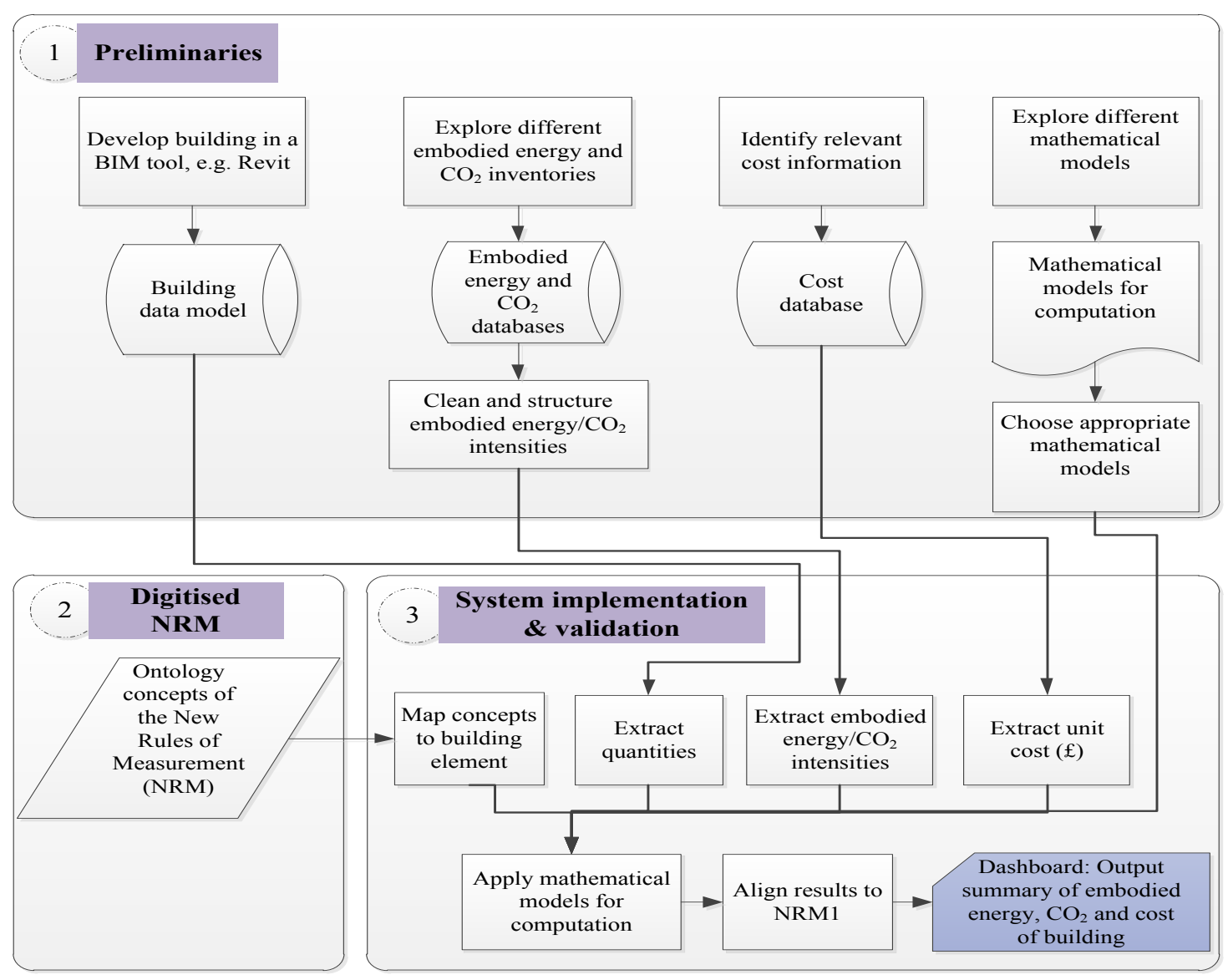

259 Fig. 1. Integrated framework for automatic BIM-based computation of embodied energy/ $\mathrm{CO}_{2}$ and cost

\section{Mathematical modelling techniques for computing embodied and $\mathrm{CO}_{2}$}

263 A mathematical model of a real object is a totality of logical connections, formalised

264 dependencies and formulas, which enables the studying of real world objects without its 265 experimental analysis (Gertsev and Gertseva 2004; Kundzewicz et al. 2000). Real world 266 objects include process, phenomenon, object, element, system, etc. Mathematical models

267 typically offer convenience and cost advantages over other means of obtaining the required 268 information about real world objects (Kundzewicz et al. 2000). Most recently, mathematical 269 models have been used in decision-making about environmental impacts from waste (Hersh 270 2006). In construction projects, the focus has been on the derivation of mathematical models

271 for the computation of environmental emissions from the building life cycle (Dixit et al., 272 2010; Chang et al., 2010). The leading approaches that have employed mathematical models 273 in computing embodied energy and carbon are process, input-output and hybrid analyses. 


\subsection{Process analysis}

In a process life cycle assessment, known environmental input and output are systematically modelled through the utilisation of a process flow diagram. It is a popular method for analysing embodied energy and $\mathrm{CO}_{2}$ as it is easy to understand and project specific which allow users to compare the environmental impact of different schemes. It adopts a bottom-up approach to account for all input upstream in the process. Results from the method are considered to be accurate (Ding, 2004) and reliable (Crawford and Treloar et al., 2003) if the processes are defined accurately. The method is often criticised for its subjectivity in the definition of process boundaries being systematically incomplete (Bullard et al., 1978; Lenzen, 2001; Treloar et al., 2003), and impracticable as it is impossible to account for every single detail of every production paths of a particular building due to its diverse and complex nature (Treloar et al., 2001). Potential errors are caused by the failure to identify upstream process paths and truncation of system boundaries (Lave et al., 1995). In practice, there is also a tendency to over-simplify the processes involved due to the regular use of standard data sets with implicit exclusions, and standard models which often ignore many processes (Treloar et al., 2001). The accuracy of this method highly depends on the dataset which is often quantified in terms physical consumption data, e.g. kWh of electricity, tonnes of aggregates and kilograms of food.

\subsection{Input-output (I-O) analysis}

The concept was first developed by economist Wassily Leontief (Leontief, 1966) to predict the effect of changes in national average data of an industry on others by using a matrix to show the relationship (Leontief 1966; 1970). The concept has been extended to apply to other fields including environmental impact assessment by replacing economic exchanges to energy exchanges. The I-O analysis gained favour from researchers as the system boundary is considered as comprehensive and complete (Treloar, 1997; Suh and Huppes, 2002) disregarding that its 'black box' nature is often being criticised as lacking transparency.

Contrast to the process analysis, it is a top-down method that uses average material price data to assess embodied energy. This technique is very suitable in situations where the physical consumption data of process or products are not available (Simmons et al., 2010). It uses the financial I-O tables to estimate average $\mathrm{CO}_{2}$ associated with each $£$ of spending within a given sector of a national economy. The application of I-O analysis for the evaluation of individual building projects is very limited as the approach and data used is not sophisticated 
enough to distinguish differences between specific project aspects. It is more suitable for the estimation of the overall impacts of products on a regional, national or international level or for scoping exercise. Some weaknesses are common with the I-O analysis method. Firstly, the method include the presence of potential errors resulting from the proportionality assumption (i.e. input to a sector is assumed to be linearly proportional to its output) and homogeneity assumption (i.e. output from a sector is assumed to be proportional to their price), and additional errors due to conversion of prices to embodied energy (Lenzen, 2001). Secondly, the I-O tables used in the estimation of physical flows of materials through the economy are highly aggregated. Third, the I-O data tables are often too old and out-dated.

\subsection{Hybrid analysis}

Various attempts have been made by researchers to combine the process analysis and I-O analysis to overcome the problems of the two individual methods described above (e.g. Bullard et al., 1978; Oka et al., 1993; Lenzen, 2002). Early approach to combine the two methods is often referred as process-based hybrid or tiered hybrid analysis. Generally, the tiered hybrid method aims to improve the completeness of results while keeping process specificity by aggregating the process analysis results that cover near upstream processes as prescribed in the process flow identified and input-output analysis results that cover far upstream processes beyond the process flow identified. An operational tool called Missing Inventory Estimation Tool (MIET) (Suh and Huppes, 2002), which has been further developed to a commercial software, SimaPro, is available to support the tiered hybrid method for life cycle analyses studies. Although the tiered hybrid is able to complete the system boundaries for components upstream from the process flow due to the use of I-O data, it inherited major limitations of process analysis. For instance, the method still relies heavily on the user's input in defining processes which remains the main cause for truncation errors. Besides, since the method involves the translation of I-O data, i.e. total energy intensities for materials (in $\mathrm{MJ} / \mathfrak{f}$ ), to embodied energy (in $\mathrm{MJ}$ ) by multiplying average product prices, any pricing errors could easily bias the results (Treloar, 1994). The second form of hybrid analysis uses the input-output data as the basis. The method disaggregates part of the I-O data from an I-O model to enhance process specificity. Treloar (1997) developed a systematic technique to extract significant embodied energy paths from the I-O data. Activities for those process data which are available are first identified. Values for identified energy paths are then replaced by those calculated using process data. Thus, the holistic nature of I-O analysis 
is preserved. The technique is further applied to conduct embodied energy analysis for individual buildings (Treloar et al., 2001). The study demonstrates that case specific data can

343 be integrated into I-O based model. Similar methods have been used in subsequent embodied 344 energy studies (e.g. Lenzen (2002)). The I-O hybrid method does have limitations mainly inherited from the I-O nature. Firstly, the method alone cannot be used to assess the whole life cycle of a product as I-O data does not cover the use and end-of-life stages. One solution is to use it together with process method or tiered hybrid method to cover the two outstanding stages. By integrating with a process-based method, the completeness of the system is again doubtful. Secondly, the method is not suitable for analysing an element or a component of individual buildings because it is not possible to disaggregate I-O data by specific elements or components.

The approach adopted in this work is based on matrix algebra inherent in input-output which at the same time encapsulates linear functions common in process approaches. However, instead of using financial I-O tables to estimate average embodied energy and $\mathrm{CO}_{2}$ associated with each $£$ of spending within a given sector of a national economy, we have chosen the content or entries of the matrix tables to represent directly the quantity of material used in a building project. Thus, the weakness often associated with the dependence on outdated I-O tables that only provide average embodied energy and/or $\mathrm{CO}_{2}$ is avoided. The matrix-based models examined in the British Standards (BS 2010) provide a good starting point and was adapted for embodied energy and $\mathrm{CO}_{2}$ assessments in this study.

Let's suppose the different work break down packages are categorised into $m$ group elements denoted $G E_{i}, i=1$ to $\mathrm{m}$. Suppose there are $n$ building elements $B E_{j}$ with each quantity $q_{i j}, j=$ 1 to $n$. Let's suppose the embodied energy intensity of each building element $B E_{j}$ be $e_{j}$. The embodied energy, $E E_{i}$, of each group element can be computed as:

367

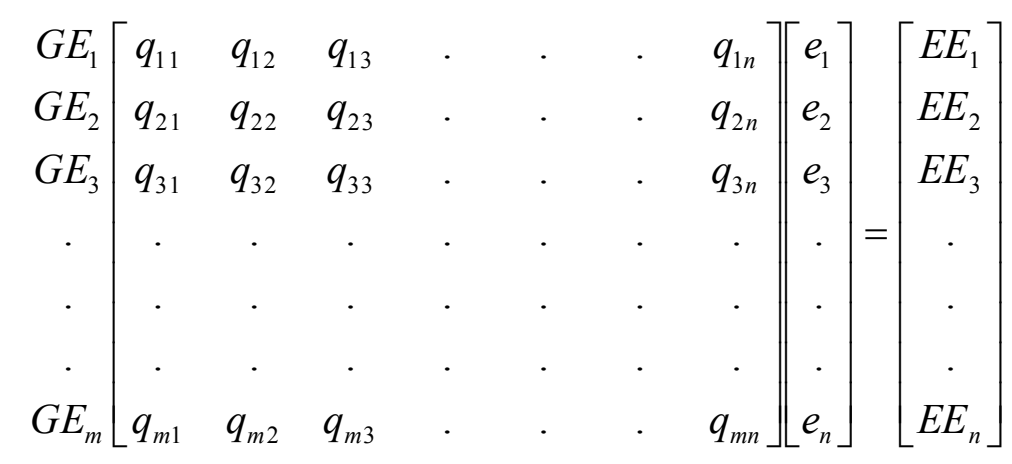


370 The embodied energy for a work package is:

$371 \quad E E_{i}=\sum_{j}^{n} q_{i j} e_{j}$

372 The total embodied energy for the whole building is:

$$
T E=\sum_{i=1}^{m} E E_{i}=\sum_{i=1}^{m}\left\lfloor\sum_{j=1}^{n} q_{i j} e_{j}\right\rfloor
$$

374 If the waste factor $\mu_{j}$ is considered then:

$$
T E=\sum_{i=1}^{m} E E_{i}=\sum_{i=1}^{m}\left\lfloor\sum_{j=1}^{n}\left(1+\mu_{j}\right) q_{i j} e_{j}\right\rfloor
$$

376 Similarly, considering the embodied $\mathrm{CO}_{2}$ intensity, $e c_{j}$, of each building element $B E_{j}$, and

377 waste factor $\lambda_{j}$, the total embodied $\mathrm{CO}_{2}$ of the building is:

$378 \quad T E C=\sum_{i=1}^{m} E C_{i}=\sum_{i=1}^{m}\left\lfloor\sum_{j=1}^{n}\left(1+\lambda_{j}\right) q_{i j} e c_{j}\right\rfloor$

380 All the variables in equations 4 and 5 can be obtained from the building model in Revit except $e_{j}$ and $e c_{j}$ that should be sourced from inventory databases. To this end, leading inventory databases were reviewed to identify suitable embodied energy and $\mathrm{CO}_{2}$ intensities. Some examples include Bilan Carbone developed by the Agence de l'Environnement et de la Maîtrise de l'Energie (ADEME) (ADEME, 2017), the Bath Inventory of Carbon and Energy (ICE) developed by Hammond and Jones (2008) at the University of Bath, UK, Emission

386 Factor Database (EFDB) developed under the coordination of the Intergovernmental Panel on Climate Change (IPPC) (EFDB, 2017), the Eco-Inventory (a.k.a ecoinvent) developed by the Swiss Centre for Life Cycle Inventories (SWLCI) (ECO, 2017) and GaBi, a life cycle sustainability assessment tool developed by Thinkstep, based in Leinfelden-Echterdingen, Germany ( $\mathrm{GaBi}, 2017)$. On examining the afore-mentioned database inventories, three main findings emerged. Firstly, the scope of ADEME, EFDB, ecoinvent and GaBi are wider and contains intensities of materials of many sectors compared to Bath ICE that focuses only on construction materials. Secondly, the embodied energy and $\mathrm{CO}_{2}$ intensities in all the databases are structured differently, talk less of being aligned to any standard measurement methods. Thirdly, all the inventory databases contain only non-geometric data, implying that professionals or experts will still have to manually extract the embodied energy and $\mathrm{CO}_{2}$ 
intensities and combine these with geometric data of buildings to manually compute the embodied energy and embodied $\mathrm{CO}_{2}$ in a separate system. This is very time consuming, tedious and error prone. We proposed a system that builds on the preceding weaknesses by first of all choosing Bath ICE for the $e_{j}$ and $e c_{j}$ because of its focus on construction and also because the case study building is based in the UK. Furthermore, our BIM-based approach integrates geometrical and non-geometrical data, computes embodied energy and embodied $\mathrm{CO}_{2}$ and then finally aligns the results to standard measurement methods. By doing so, the results automatically align to cost data structured in according to standard measurement methods, in this case the NRM 1.This allows experts to conveniently consider environmental performance as well as cost of buildings, which is not obtainable with database inventories that essentially deal with single products/materials data or a simplistic combination of data for composite components.

\section{Digitising New Rules of Measurements}

In the UK, New Rules of Measurements are amongst the leading professional documents used for construction material quantification and cost estimation. Currently there are two versions. RICS New Rules of Measurement 1 (NRM 1) provides fundamental guidance on the quantification and description of building works for the purpose of cost estimation and cost plans (RICS, 2009). It provides a standard set of measurement rules that are understandable by all those involved in a construction project. RICS New Rules of Measurement 2 provides fundamental guidance on the quantification and description of building works for the purpose of preparing bill of quantities and quantified schedules of works. It also provides a sound basis for designing and developing standard or bespoke schedules of rates (RICS, 2012). However, the UK New Rules of Measurement is not electronic and professionals often edit the different work break down structure using Spreadsheet for their different purposes. The current format of the UK New Rules of Measurement is not yet integrated in BIM tools and has already been criticised by Olatunji et al. (2010) and Wu et al. (2014). Consequently, it was imperative to develop an ontology of the New Rules of Measurement that can facilitate the take-offs of construction materials for embodied energy and $\mathrm{CO}_{2}$. The NRM 1 breaks building works into 15 group elements, numbered from 0 to 14 . The most important group elements are 0-8 (RICS, 2012, pp.24). The different group elements are Group 0: Facilitating Works; Group 1: Substructure; Group 2: Superstructure; Group 3: Internal Finishes; Group 4: Fittings, Furnishes and Equipment; 
430 Group 5: Services; Group 6: Prefabricated Buildings and Building Units; Group 7: Work to

431 Existing Buildings and Group 8: External Works. Each of these groups is further broken

432 down into elements. For example, Group 3: Internal Finishes is broken down into 3, namely,

433 Wall Finishes, Floor Finishes and Ceiling Finishes. The NRM 1 data is text-book-based and

434 hence presents challenges on how to be edited into the proposed system. The knowledge

435 engineering techniques used to capture the concepts have been discussed in Abanda et al.

436 (2015). Based on Abanda et al. (2015), the key ontological concepts, i.e. classes, sub-classes,

437 object properties, data type properties and instances were manually identified and elicited

438 from NRM 1 book. The manually elicited ontological concepts were manually edited into

439 Protégé-OWL 3.5. Protégé-OWL 3.5 is one of the leading ontology/knowledge engineering

440 editors developed by the Stanford Centre for Biomedical Informatics Research (BMIR),

441 Stanford University, USA. It offers two main benefits that cannot easily be obtained from

442 using traditional software such as MS Excel. Firstly, concepts and sub-concepts can easily be

443 created in Protégé-OWL, not straight-forwardly done in MS Excel. Secondly, Protégé-OWL

444 facilitates the checking of duplicated classes or concepts. Editing repeated terms are not

445 allowed in Protégé-OWL and the software will alert if there is a duplicated term. This facility

446 is not present in MS Excel. This study goes beyond top level ontological concepts provided

447 by Abanda et al. (2015) to detail sub-classes of concepts and instances of the Fittings,

448 Furnishes and Equipment (Group 5) Services (Group 6) of the NRM 1. Using Protégé-OWL

$4493.5,942$ concepts were captured. An excerpt of the NRM 1 electronic ontology is presented

450 in Figure 2. The complete developed electronic NRM 1 was integrated into the proposed

451 system. The details of this integration process, mathematical models used and the undertaking

452 of activities in part 1 (i.e. preliminaries) of Figure 1 (i.e. research framework) will be

453 discussed in the sixth and seventh sections.

454 


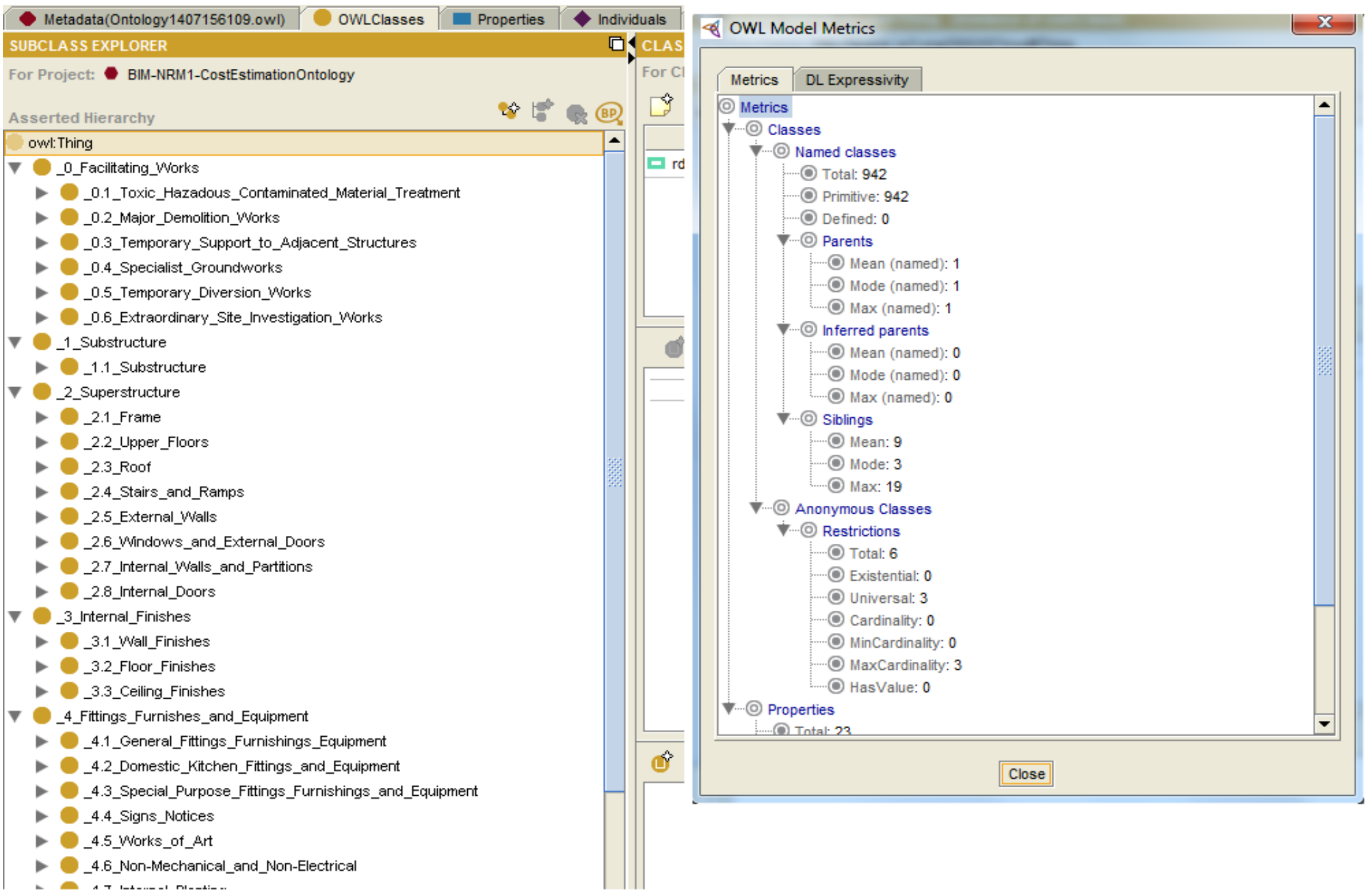

456 Fig. 2. An excerpt of the NRM 1 of measurement ontology 


\section{Framework Implementation}

459 The implementation algorithm of the proposed system is presented in Figure 3. It is a

460 simplified flow chart of actions and processes split into two blocks: user initiated process and 461 the system executed processes. Actions and processes carried out by the user fall under user

462 initiated processes while the corresponding feedback of the system and subsequent system

463 triggers required in completing the various steps are captured under system executed process.

464 Three key parameters need to be considered before commencing the embodied energy and

$465 \mathrm{CO}_{2}$ assessment process. The project location, type of house and the rule of measurement

466 need to be provided by the user. The latter determines the work break down concepts which

467 serve as placeholders for the editing of corresponding material drawn from the system

468 database. Once this process is repeated for all required material, the automatic computation of

469 embodied energy and $\mathrm{CO}_{2}$ is triggered and results aligned with NRM 1. 


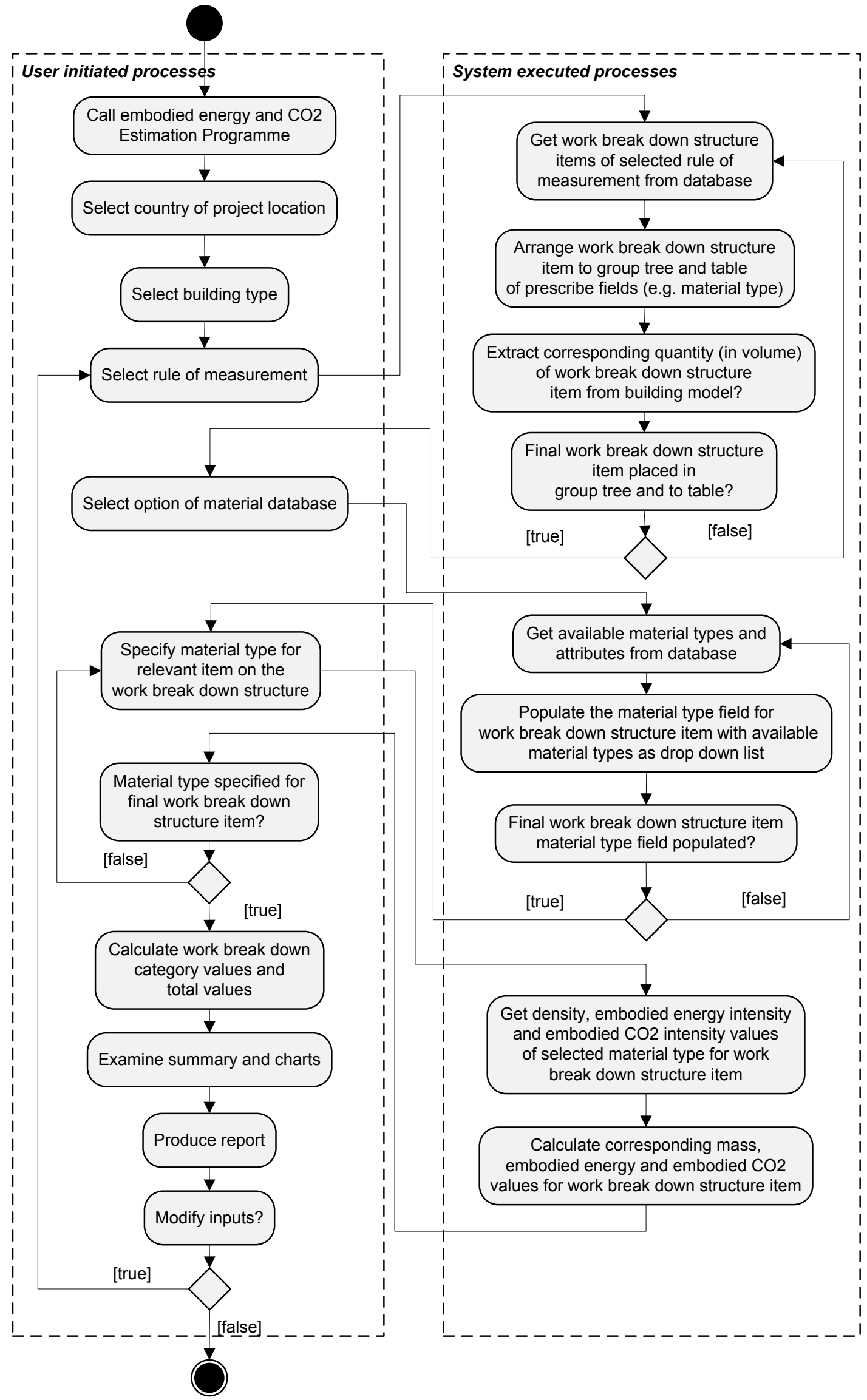

Fig. 3. Algorithm for NRM based embodied energy and $\mathrm{CO}_{2}$ assessment 


\subsection{Transformation of the ontology for use in the proposed system}

476 As mentioned earlier, a total of 942 concepts from the NRM 1 have been captured in Protégé-

477 OWL. Producing a NRM 1 XML format of the ontology from Protégé-OWL made it possible 478 to load the generated XML based NRM 1 work break down structure into Navisworks 479 Manage 2015 from where it was exported to MS Excel spreadsheet. The choice of

480 Navisworks is based on the fact that it can be used to perform quantity take-offs (QTO) while the orderly hierarchical structure of the developed NRM 1 XML-based ontology is preserved. However, before making a firm decision to use Navisworks, authors explored other similar software such as BIMiTs and Solibri Model Checker. BIMiTs functions as an extension (addin) for Autodesk Revit offering solutions for workflows and information exchange with structural analysis/detailing packages and spreadsheets such as Excel. On the other hand, Solibri Model Checker ${ }^{\mathrm{TM}}$ is used in analysing building information models for integrity, quality and physical safety to reveal potential flaws and weaknesses in the design, clashing components and compliance with the building codes/best practices. While these packages are great in enhancing the process of information exchange they are limited in accommodating the structuring of exported data to prescribed standard measurement format such as NRM 1.

492 Although, QTO can be performed in Revit, it is not a specialised tool for QTO. This is 493 exacerbated by the fact that, once quantities are generated from Revit, the output is not 494 aligned to any standard measurement methods and hence not structured. Specialised QTO 495 (e.g. Navisworks) and cost estimating tools allows for quantities to be aligned and hence structured in an orderly and easy to read manner. Similar to Uniformat, CSI-16 and CSI-48,

497 having the NRM 1 in Navisworks allow for quantities to be taken off from an imported model

498 from any BIM authoring tool in a format understandable and readable by Navisworks.

499 Navisworks can read formats such as IFC, .RVT, DWG, etc. Once the model is in

500 Navisworks, then QTO can be conducted in alignment with the NRM 1. Reading the

501 developed NRM 1 - XML based ontology with Excel from Protégé-OWL without

502 Navisworks as intermediary led to a huge loss in the structure and number of concepts. When

503 Navisworks is used as an intermediary the loss of structure and number of concepts is

504 minimised. The output from Navisworks is presented in Figure 4. There were a total of 6

505 level groups of information (Figure 4) (i.e., Groups (Group i: i = 1...6) representing column 


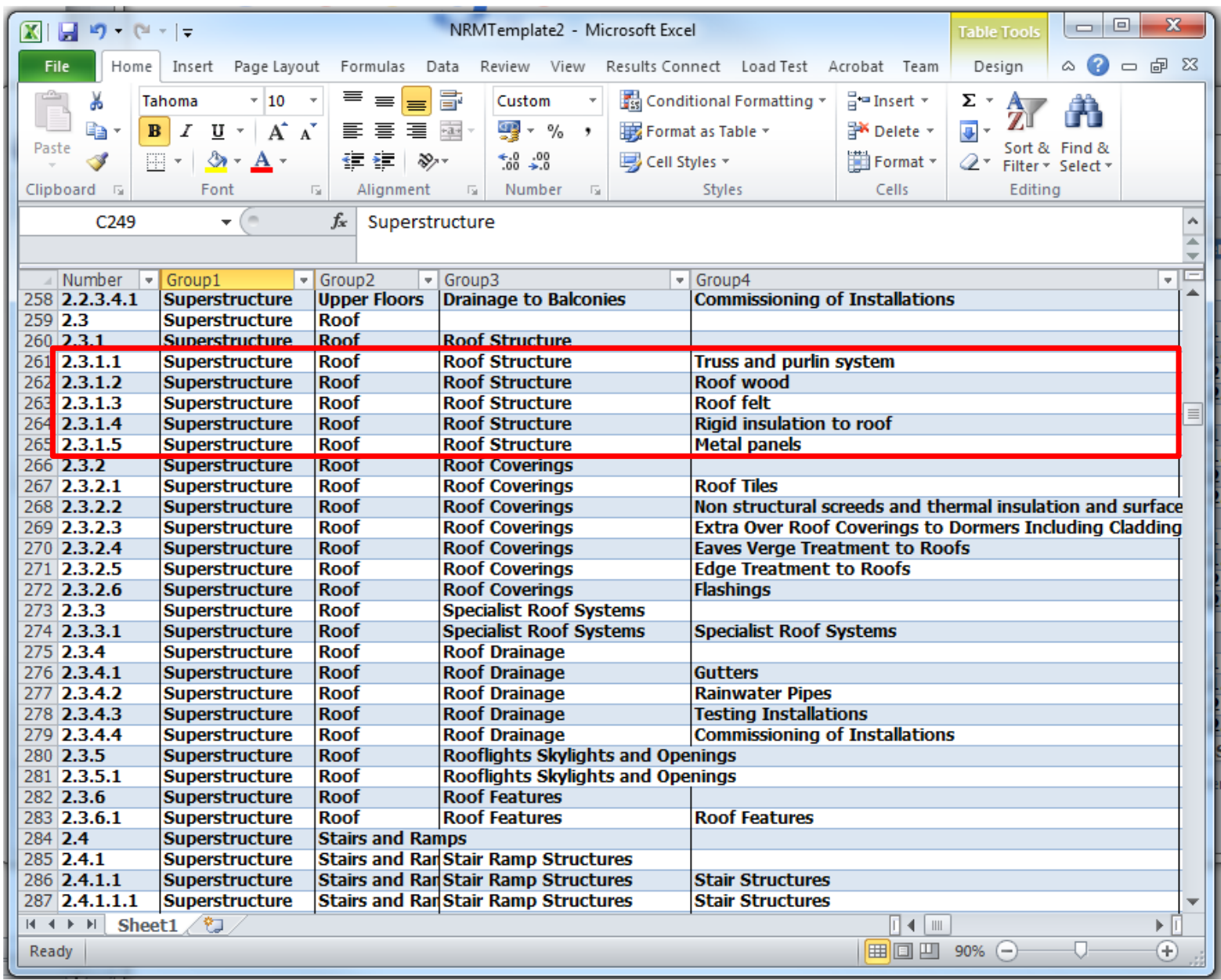

513 The level of detail on the sixth group or column is such that the fifth and in some cases the

514 fourth level is repeated as a single entry but this was to allow for future expansion of the

515 ontology. As such, up to the fourth group level was covered and a total of 885 entries were

516 abstracted from the XML based NRM 1 work break down structure. This is less by 57

517 concepts in the original NRM 1 ontology developed in Protégé-OWL. In order to conform to

518 existing structure of traditional bill of quantities and to enhance the mapping of information

519 from Revit material database the 57 concepts were manually edited into our proposed system.

520 For example, in the Group 4 column, entry numbers 2.3.1.1 to 2.3.1.5 has been manually

521 edited to Truss and purlin system, Roof wood, Roof felt, Rigid insulation to roof, Roof felt

522 and Metal plate and mapped to Revit material database (see Figure 5). 


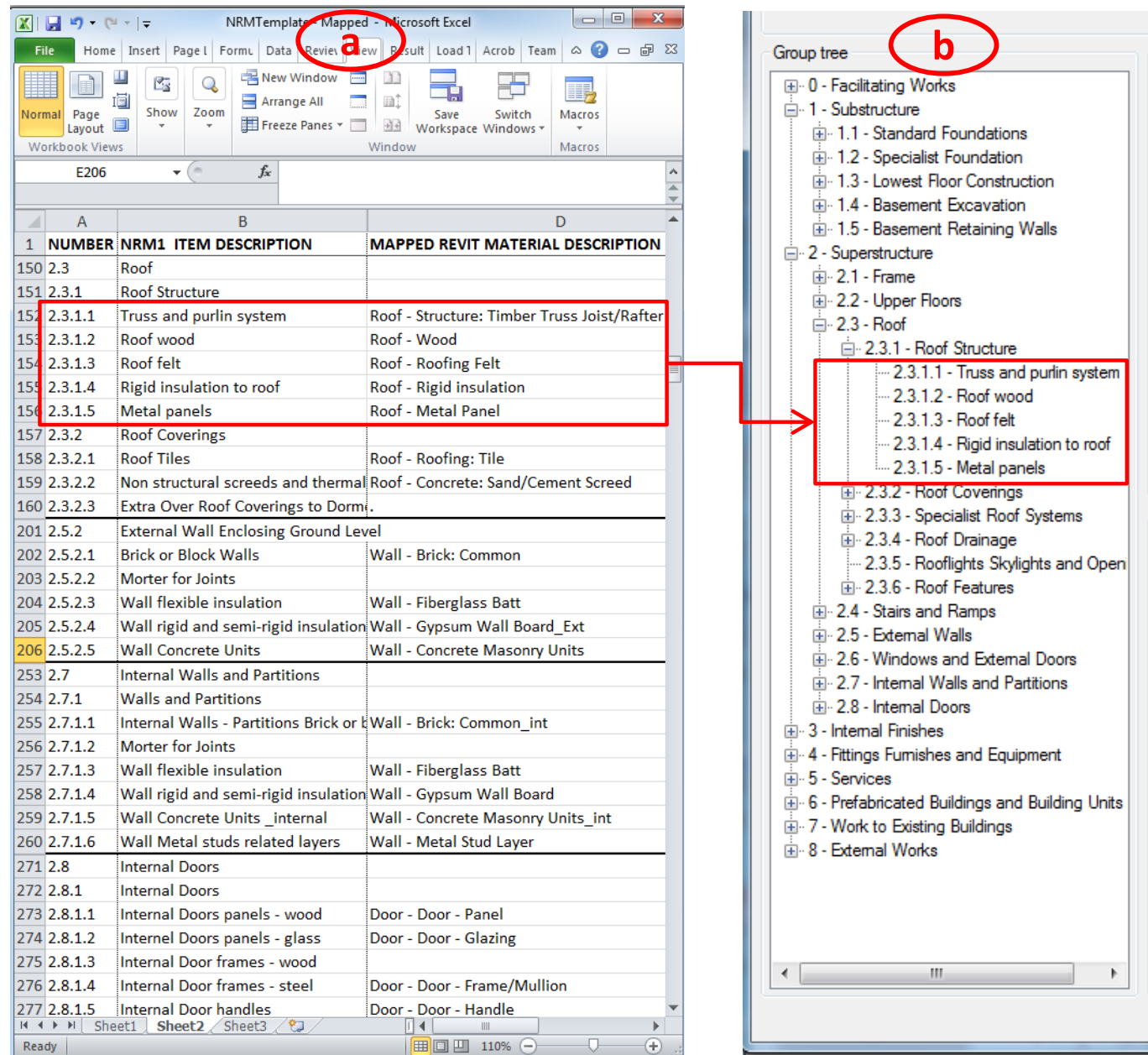

525 Fig. 5. Transforming NRM 1 XML based concepts to the proposed system (a) Mapped NRM

\section{$528 \quad 6.2$ System architecture}

529 The concept of the model implementation is captured in the system architecture illustrated in 530 Figure 6. 
CONTROL

(Rules of measurement)

- NRM1

- SMM7

- UNICLASS

INPUT

- Project information

- Location (country)

- Building type

- Material quantities

Fig. 6. System architecture

534 Figure 6 is an IDEF0 (Icam (Integrated Computer Aided Manufacturing) DEFinition for

535 Function Modelling 0) representation of key parts of the implementation. On the input side,

536 the project information together with the building type and material quantities of items serves

537 as the requirements supplied by the designer or user for the programme to commence. The

538 items are listed based on the selected standard rules of measurement method which is the

539 Control. On the part of the Mechanism, the material database of density, embodied energy

540 and $\mathrm{CO}_{2}$ intensities work as the elements for the system to calculate the actual embodied

541 energy and $\mathrm{CO}_{2}$ values based on the supplied items and their quantities in volume. The

542 volume of the material is combined with density values obtained from the database to

543 calculate the mass which is subsequently used in the process to compute actual embodied

544 energy and $\mathrm{CO}_{2}$ parameters of the items. Also obtained from the database are embodied

545 energy and $\mathrm{CO}_{2}$ intensity values of materials for the computation. These are further combined

546 to yield the work break down structure values and the total values as the output of the system.

547 The details captured in Figure 6 have been expanded and presented in Figure 7. 


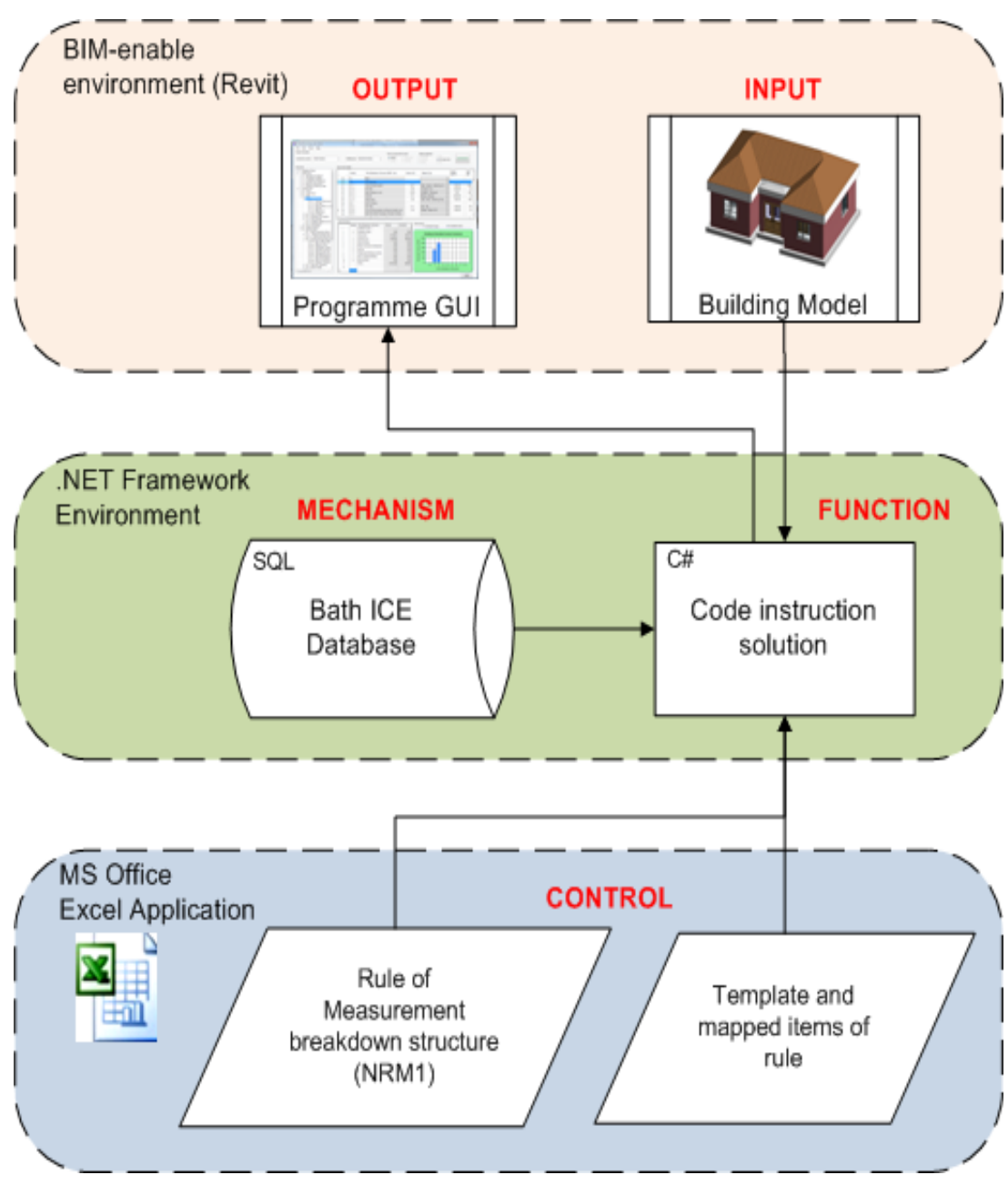

Fig. 7. System implementation modules

552 The programme, implemented in $\mathrm{CH}$, is basically made of three modules. The first module is the MS Excel application spreadsheets containing the grouped information of NRM 1 rule of measurement work break down structure with a consistent supporting mapped items template

555 file. The NRM 1 work break down structure grouped information serves as source file for

556 composing the tree structure to facilitate moving around the work break down structure

557 categories and the list of items. The mapped item template on the other hand controls the

558 loading of work break down structure items into the system (Function) and placement of

559 volume information extracted from the model into a data grid. This module has the potential

560 of being expanded to take more templates such as Standard Method of Measurement 7

561 (SMM7), Civil Engineering Standard Method of Measurement (CESMM) and Unified

562 Classification for the Construction Industry (UNICLASS). Operations in the .NET

563 environment make up the second module. A structured query language (SQL) database and 
564 the $\mathrm{C \#}$ code instruction solution are contained in this module. The database information is 565 compiled from existing material databases such as the Bath Inventory of Carbon and Energy

566 (Bath ICE) used in this implementation. Other material databases, if and when available can

567 be incorporated into the database. The SQL database is embedded in the C\# environment

568 where the actual programme coding instructions have been instantiated. The coding takes

569 advantage of the object-oriented nature of the language to achieve intended goals. The third

570 module is the BIM-enable environment where the programme is initiated, triggering the input

571 into the system and corresponding output of responses in the graphical user interface (GUI).

572 The program is linked to the BIM environment as external add-in tool through an

573 implemented Application Programming Interface (API) application. The key inputs are

574 quantities of materials automatically extracted from the building model. The quantities can be

575 edited or optionally entered manually. The output consists mainly of the Embodied Energy

576 and $\mathrm{CO}_{2}$ Windows Form. The form contains all the visual display of the programme. It

577 provides the medium for entering other input information and displaying output responses.

578 Underlying the form is the earlier mentioned second module (i.e. Mechanism and Function

579 implementation in .NET Framework) which is a combination of programming instantiations

580 and mathematical algorithms simulating material information from the database in

581 accordance to the specified rules of measurement. Figure 8 shows the dependency diagram

582 generated in the C\# environment. 


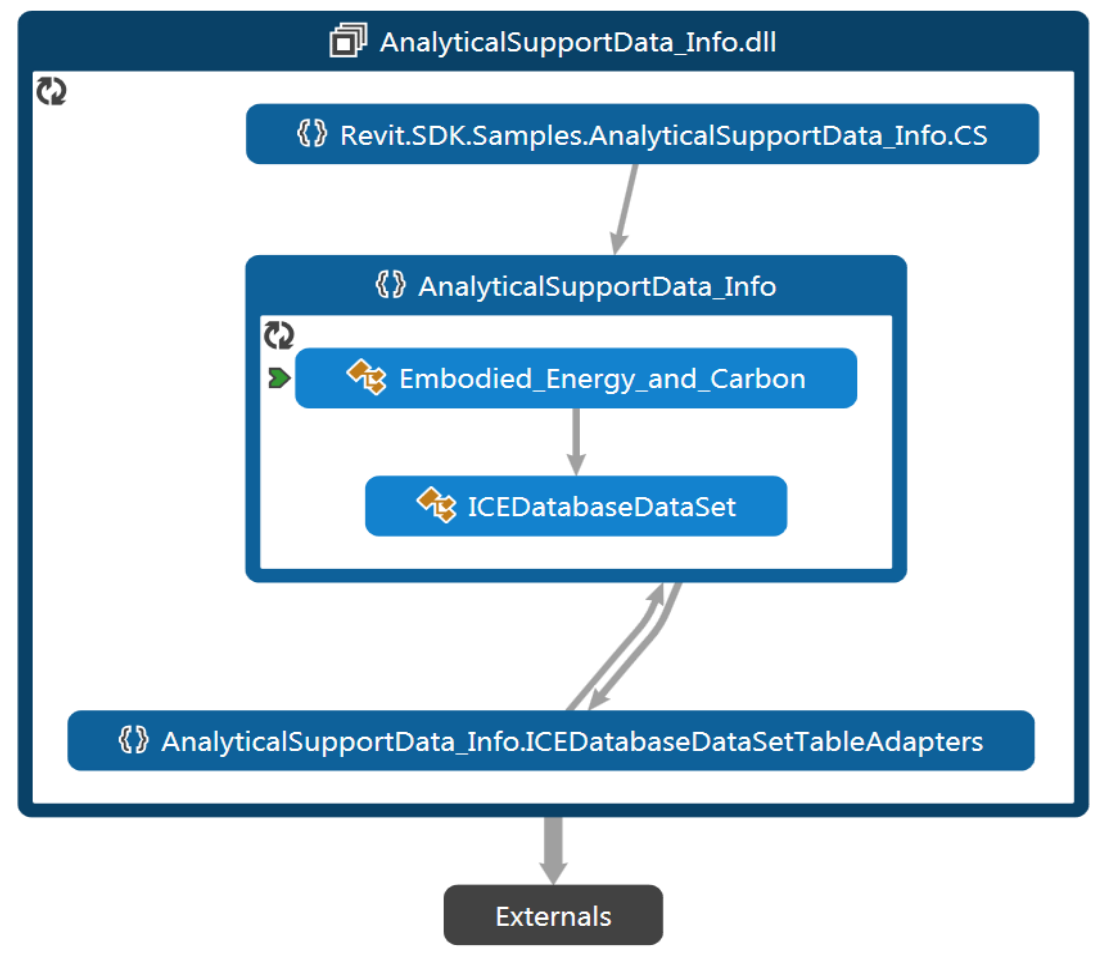

Fig. 8. System dependency diagram

586

587 In Figure 8, the AnalyticalSupportData_info.dll is the external command handle through

588 which Revit program calls the proposed embodied energy and $\mathrm{CO}_{2}$ analysis programme. The

589 Externals block contains the .dll reference files for Revit API, Windows and System

590 operations. The graphical user interface of the proposed programme is the Windows form

591 represented by Embodied_Energy_and_Carbon in the figure. It has direct link to the

592 ICEDatabaseDataSet which is generated from the SQL database of Bath ICE material

593 database, all operating under the AnalyticalSupportData_info programming namespace.

\subsection{System operation}

596 In this implementation, the key is the extraction of quantities from a BIM authoring software.

597 There are two approaches - one manual and the other automatic. In the manual, the user can 598 generate quantities from a BIM authoring software, in this case Revit and manually enter 599 them into the system. In the automatic process, the system automatically extracts quantities of

600 the different building components from the building model in Revit environment and fits

601 them into in the New Rules of Measurement catalogues. We opted for the latter as it is

602 quicker and not prone to errors like the manual. The automatic extraction and alignment to 

program is illustrated in Figure 9.

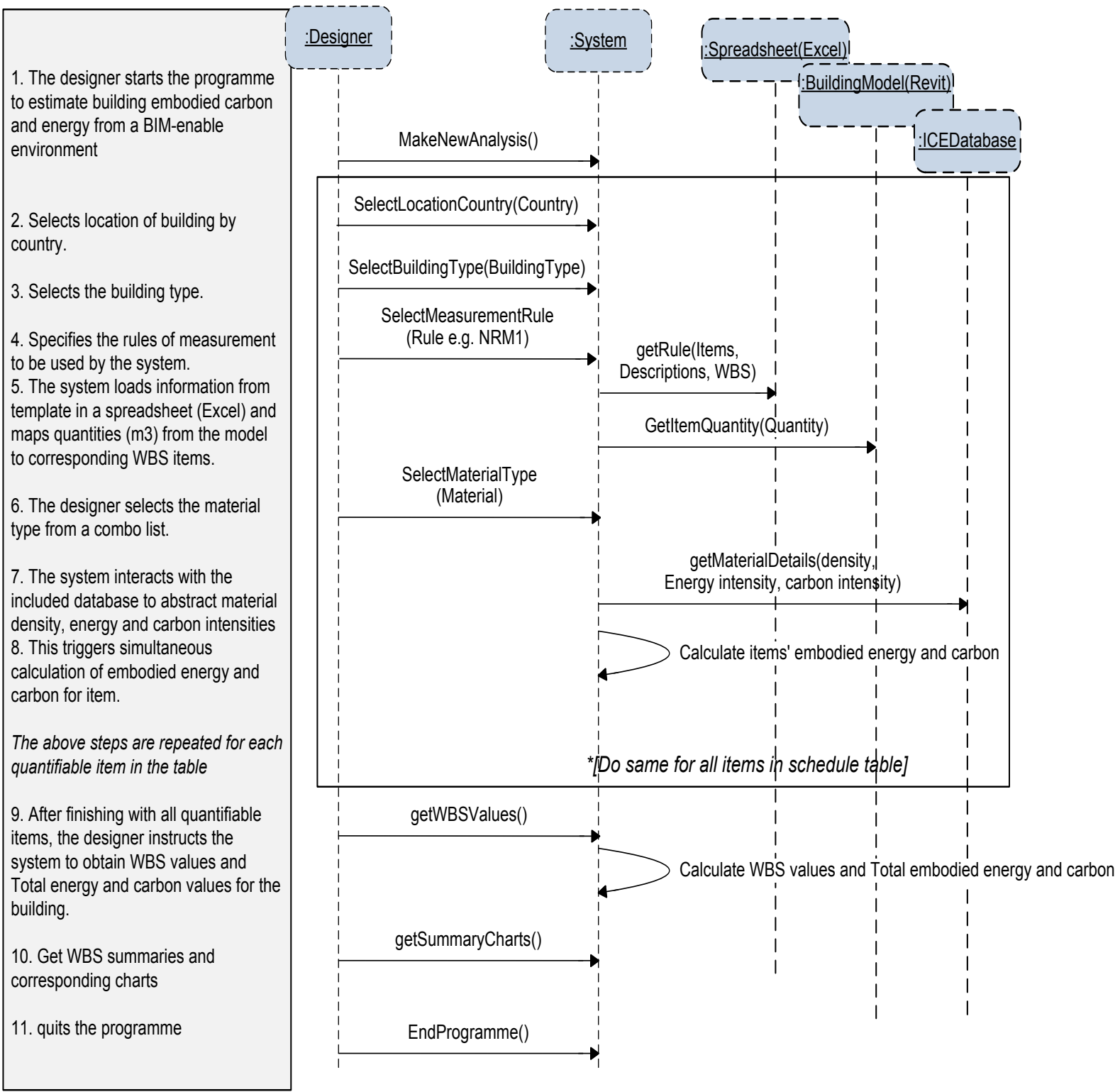

609 Figure 9 is a system sequence diagram outlining the functions of the designer/user and the

610 system. The sequence diagram has been programmed as depicted in the Graphical User

611 Interface of the system presented in Figure 10 for clarity purposes. The operation can be

612 carried out in 11 major steps from start to finish. When the programme is (1) called from a

613 BIM-enabled environment, the designer is required to supply project information such as (2)

614 project name and location and (3) the building type before (4) selecting the rule of

615 measurement; in this case NRM 1 is to be used. In response to this, (5) the system loads the 
616 NRM 1 template from an accompanying Microsoft Excel spreadsheet in the system project

617 folder. The spreadsheet is developed as part of the Control module (See Figure 7) of the

618 system and contains the mapped information for NRM 1 item and elements in the building

619 model. The advantage of having this information in a spreadsheet is to allow for easy

620 updating of the template and for expansion to including templates of other existing rules of

621 measurement. The loading of the template into the program simultaneously triggers the

622 quantities (in volume) of materials abstracted from the building model to be placed against

623 corresponding mapped work break down structure items. The user (6) then selects the

624 corresponding material type (from a comboBox) for the item as outline in Figure 9. The

625 combo list is that of materials contained in Bath ICE material database. The selection of the

626 associated material type (7) triggers the system to communicate with material database to get

627 the density, energy and $\mathrm{CO}_{2}$ intensities and (8) the subsequent calculation of the item's

628 embodied energy and $\mathrm{CO}_{2}$. This is carried out for all the mapped quantifiable items from

629 where the work break down structure categories and total energy and $\mathrm{CO}_{2}$ values of the house

630 model (9) can be calculated on the instruction of the system by the designer. The designer

631 (10) can proceed to produce a summary of the computations and corresponding charts and

632 eventually (11) quit the programme.

633

634 Furthermore, it is important to note the interface in Figure 10 is the first view when the

635 system is launched. It functions as an extension of a plugin application, similar to that of an

636 earlier research work on the sustainability appraisal of structural steel framed building (Oti

637 and Tizani, 2015). Data values appear on the interface only when information from building

638 model has been extracted from the Revit programme shown on the background. Information

639 that is extracted from Revit includes building component names and their corresponding

640 volumes. The remaining data such as densities of materials, embodied energy and $\mathrm{CO}_{2}$

641 intensities are in-built into the database of the system and automatically links to building

642 components that comes from Revit. 


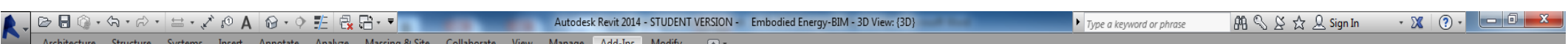

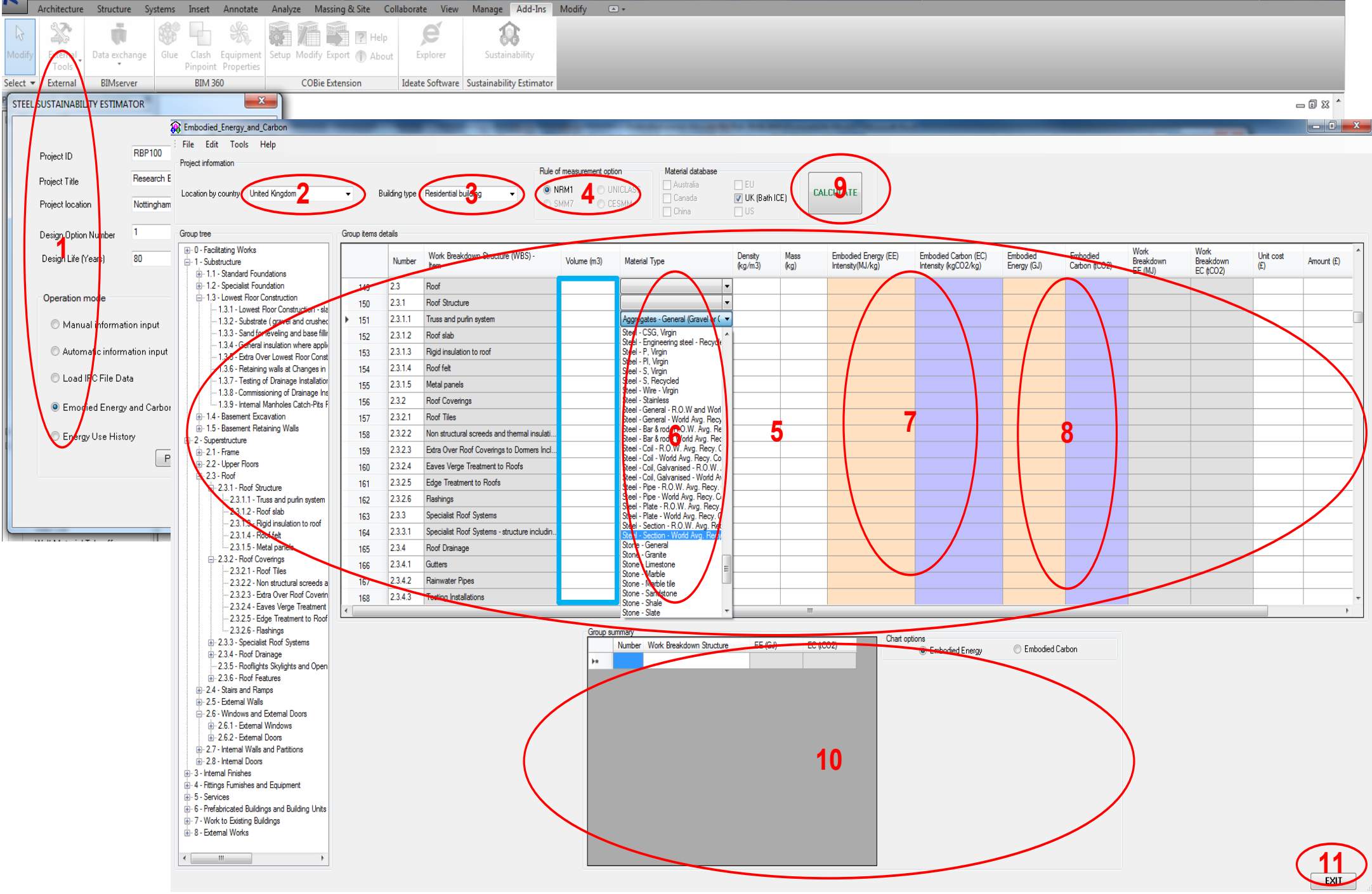

Fig. 10. GUI steps for operating the proposed system 
645

646

\section{Case study application}

647

\section{$648 \quad 7.1$ Description of a case study}

649 In this study, a house was chosen to allow for very quick evaluation and validation of

650 computational results. The house consists of a ground floor, lounge, 2 bedrooms, 1 bath

651 room, a kitchen and a dining room. The gross floor area (GFA) is $84.41 \mathrm{~m}^{2}$. The floor plan is

652 indicated in Figure 11 while the 3D model is presented in Figure 12.

653

654

655

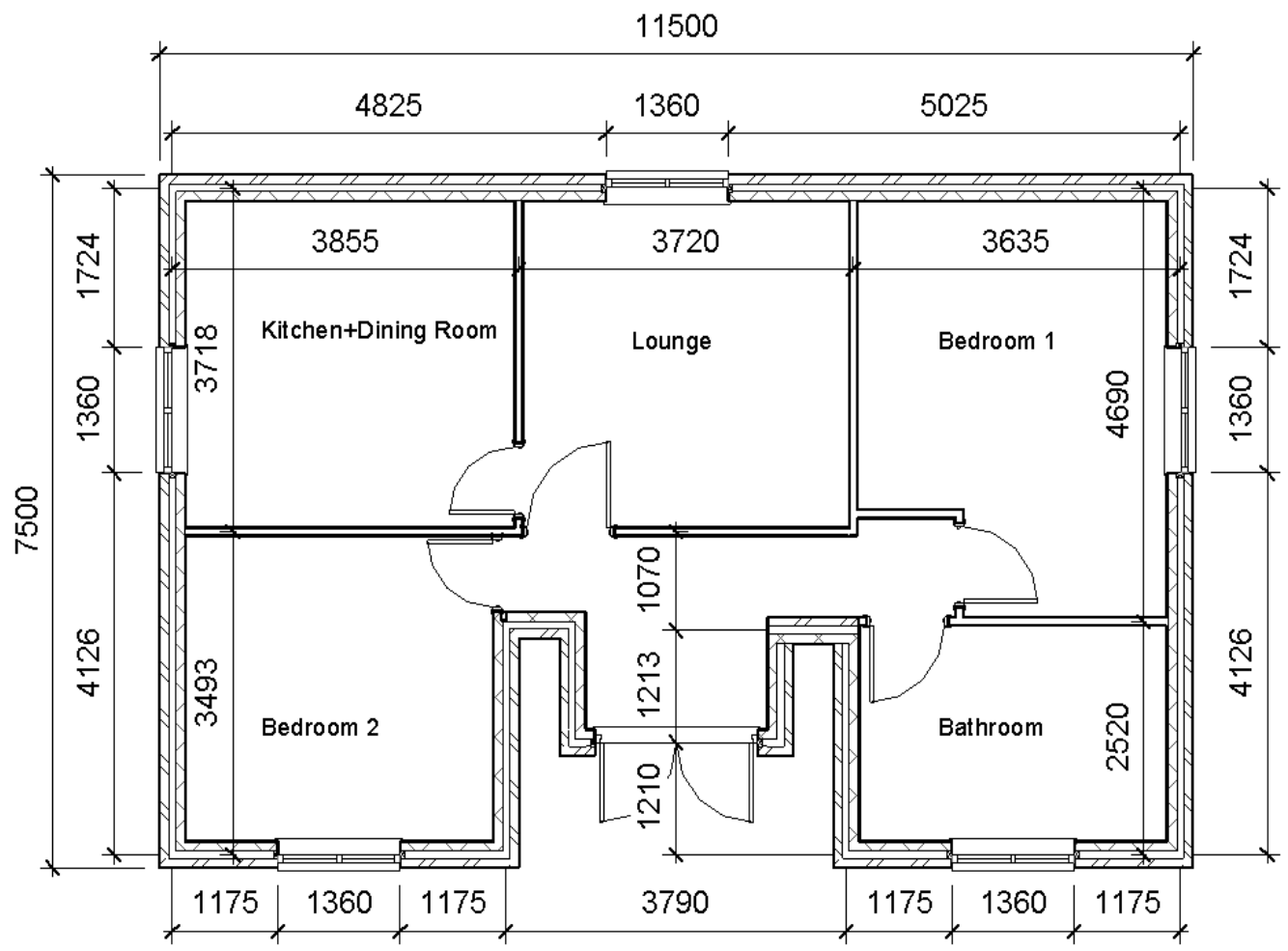

Fig. 11. Floor plan of the case study 


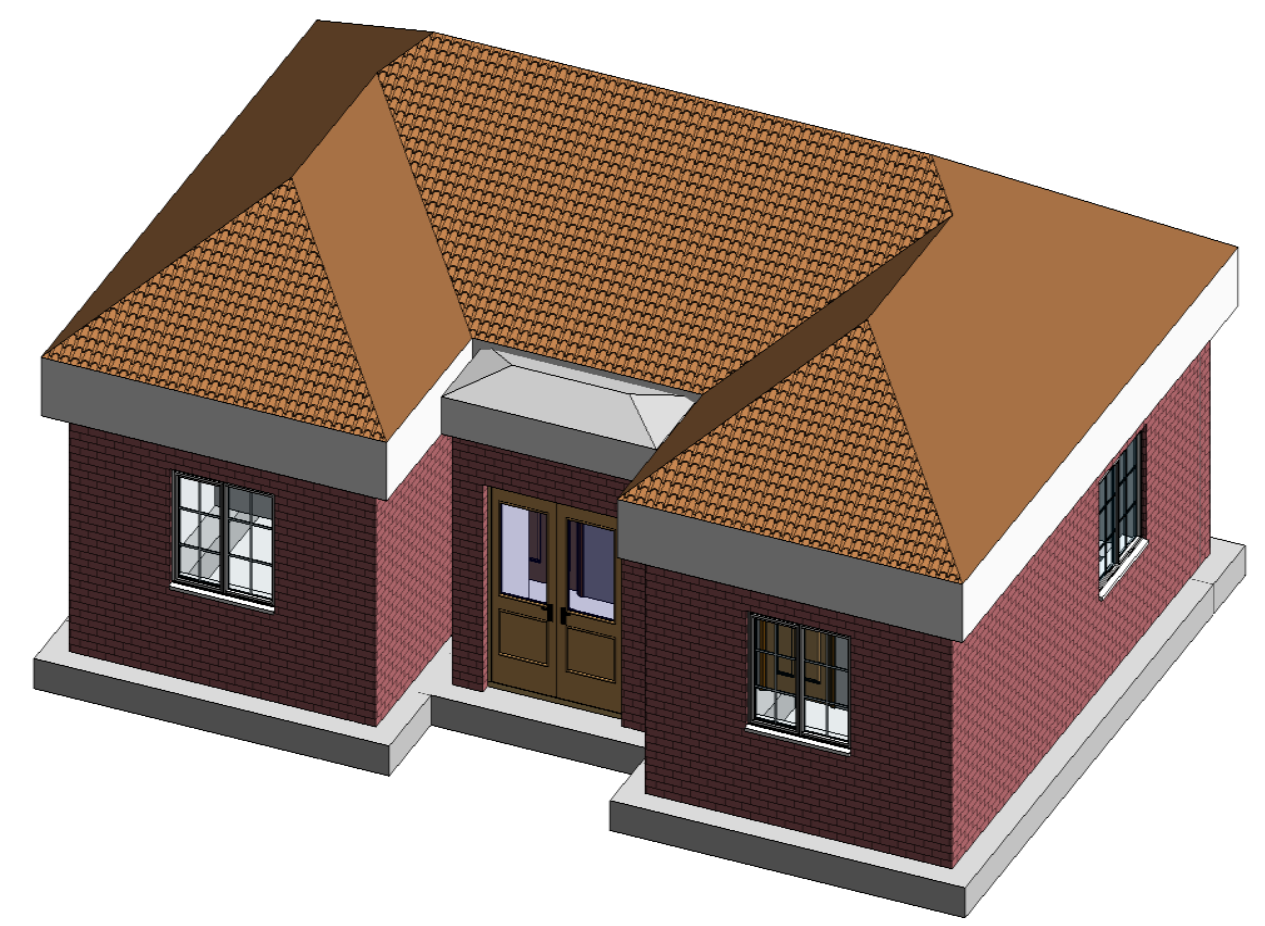

656

657

658

659

660

661

662

663

664

665

666

667

668

669

670

671

672

673

674

675

676

Fig. 12. 3D model of case study

\subsection{Application}

In this section the application of the system on a case study house will be discussed. The house is modelled in Revit, one of the leading BIM authoring software tools used in the construction industry. A script is written to read and import information from the model in Revit to the interface presented in Figure 13. The quantities are automatically extracted from the BIM model and inserted in the different NRM concepts under the Volume column discussed in Section 6.3. Once the volumes of components are extracted, all other computations are generated automatically. This includes the mass of the material item, embodied energy and $\mathrm{CO}_{2}$ intensities and the corresponding embodied energy and $\mathrm{CO}_{2}$ values according to set data grid columns. Also the total for each work break down structure is calculated and placed in the summary table with simultaneous chart output shown in Figure 13. The computations are based on the matrix Equation 2. On the completion of analysis, the embodied energy and $\mathrm{CO}_{2}$ form is visibly divided into 4 group box areas. The first is the Project information which houses the command tools for specifying inputs for project location, building type, rules of measurement, material database and the calculate button to execute an analysis. Next is the Group tree box. Here, the NRM 1 is displayed in the work break down structure hierarchy developed from the NRM 1 electronic ontology discussed in the fourth section. The tree helps in navigating around the work break down structure items in 
677 the data grid of Group item details which is the third box. The data grid is a listing of all the 678 relevant items in the NRM 1 work break down structure and provides traditional spreadsheet 679 cells (as expanded in Figure 10) containing corresponding abstracted volume values and 680 calculated information about embodied energy and $\mathrm{CO}_{2}$ of a house. Group summary is the 681 fourth which shows a summary of the eight work break down structure categories of 682 embodied energy and $\mathrm{CO}_{2}$ values, including the total for the house. This group box also 683 contains these summarized categories displayed as a chart, optionally for embodied energy or $684 \mathrm{CO}_{2}$. 
Quantities extracted from model

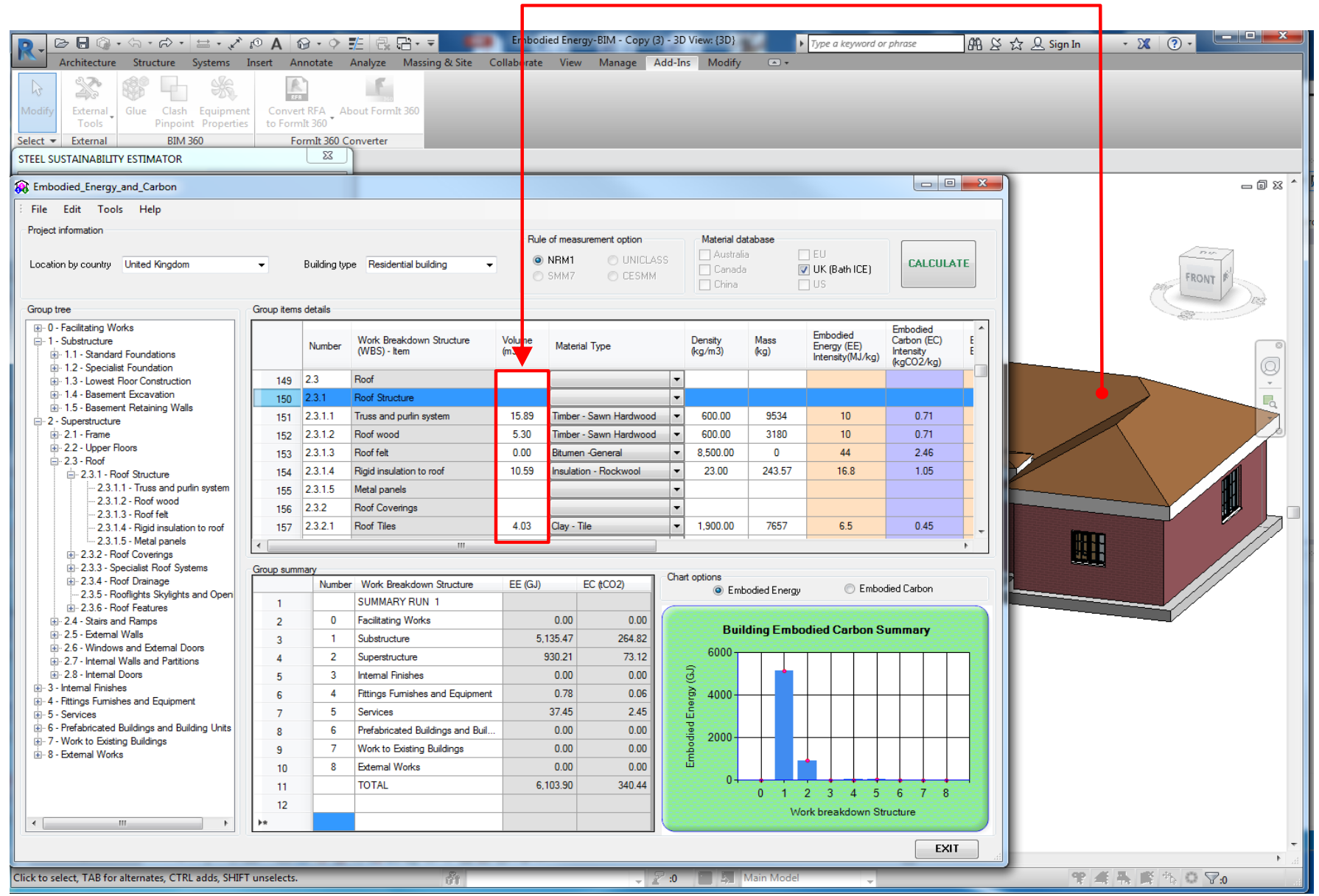

Fig. 13. A GUI of the system for automatic embodied energy and $\mathrm{CO}_{2}$ computation 


\subsection{Results, validation and analysis}

690 There are two main challenges of this study. The first is to automatically align or map

691 building components to NRM 1 concepts while the second is to extract quantities from Revit

692 to fit with NRM 1 concepts. The system is intelligent to extract the building components from

693 Revit and fits them according to the different concepts in the NRM 1 catalogue. The mapping 694 result is presented in Figure 14.

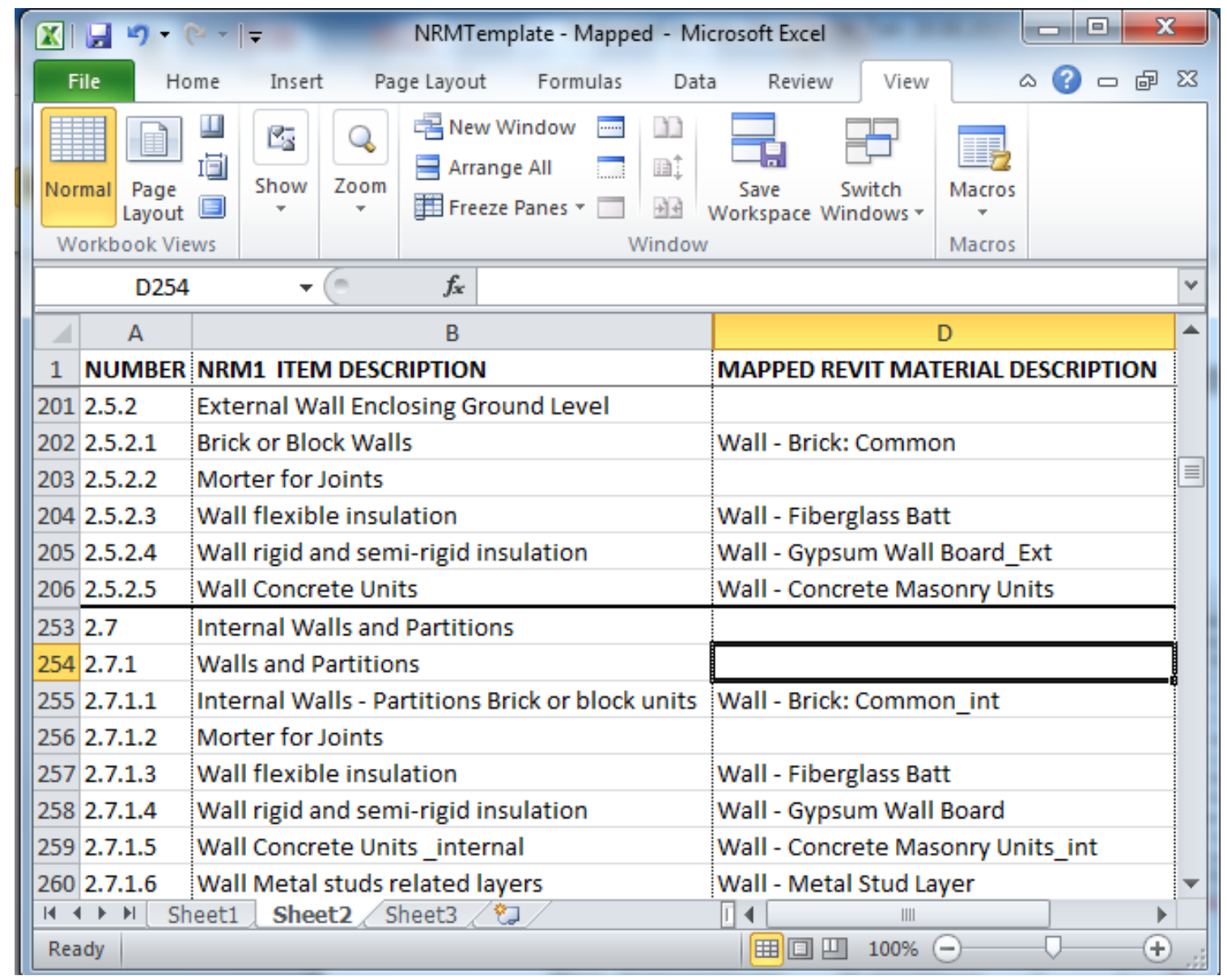

699 As shown in Figure 13, the quantities of the material components of the house model are

700 extracted, in accordance with the mappings, to the Volume column (in the Group item details

701 groupBox) of the Embodied Carbon and Energy estimation tool. Olatunji and Sher (2014)

702 argued whether estimates can be reliably generated on the basis of BIM data. This brings into

703 question the accuracy of results generated from BIM systems, especially given it is still 
emerging. Also, given that the main focus of this study is the alignment of quantities with NRM 1, while the total quantity of the model may be accurate, it is important to check whether the quantities from individual components of the proposed system have been accurately extracted and not mixed up especially for items in different categories (external and internal) of walls made up similar composite materials. Therefore it is imperative to establish whether the system sorts out quantities and aligns them accurately with NRM 1 or it mixes or inserts the quantities in the wrong or correct location. The second criterion considered was the standard error. How does the system output differ from manual computational results? The last but not the least criterion was whether quantities were extracted from all the different building components including Services or MEP? In addition to the case study building, 6 other buildings presented in Table 1 were used in verifying the validation criteria. Different types of shapes present different levels of complexity especially at the joints when modelling in BIM tools (Bazjanac, 2001). Based on shapes, number of floors, slopes of roofs and sizes parameters, additional 6 houses were selected and explored using the proposed system. To facilitate understanding, an illustration of how the standard error was computed for the roof structure, external and internal walls have been presented in the ensuing section. In addition to the standard error results, the results of the other two criteria for all the 7 case study houses have been presented in Table 1 in the Appendix.

\subsection{Roof structure and roof covering}

The output for roof structure is presented in Figure 15. The system generates volumes for different roof components as indicated in the volume column in Figure 15. To verify whether the volume values were correct or not, we went back to the model in Revit and manually computed the volumes and the results confirmed as presented with very insignificant differences. For example, from the quantity take-off, the areas of the small and bigger roofs were $4 \mathrm{~m}^{2}$ and $102 \mathrm{~m}^{2}$ respectively. The thickness of the tiles is $50 \mathrm{~mm}$. Therefore the volume is $5.3 \mathrm{~m}^{3}$ (i.e. $\left.(4+102) * 0.05\right)$ compared to $5.11 \mathrm{~m}^{3}$ extracted from Revit into our proposed system. Once the volume is pulled into the system, the corresponding density, embodied energy and $\mathrm{CO}_{2}$ intensities also appear and all other computational results such as mass in $\mathrm{kg}$, embodied energy (GJ) and $\mathrm{CO}_{2}$ in $\mathrm{tCO}_{2}$ are generated automatically. 


\begin{tabular}{|r|l|l|}
\hline & Number & Work Breakdown Structure (WBS) - ltem \\
\hline 149 & 2.3 & Roof \\
\hline 150 & 2.3 .1 & Roof Structure \\
\hline 151 & 2.3 .1 .1 & Truss and pulin system \\
\hline 152 & 2.3 .1 .2 & Roof wood \\
\hline 153 & 2.3 .1 .3 & Roof felt \\
154 & 2.3 .1 .4 & Rigid insulation to roof \\
\hline 155 & 2.3 .1 .5 & Metal panels \\
\hline 156 & 2.3 .2 & Roof Coverings \\
\hline 157 & 2.3 .2 .1 & Roof Tiles \\
\hline 158 & 2.3 .2 .2 & Non structural screeds and themal insulation and sufface treatments \\
\hline 159 & 2.3 .2 .3 & Extra Over Roof Coverings to Domers Including Cladding to Dommer Cheeks \\
\hline & &
\end{tabular}

\begin{tabular}{|c|c|c|c|c|c|}
\hline \multirow[t]{3}{*}{$\begin{array}{l}\text { Volume } \\
(\mathrm{m} 3)^{2}\end{array}$} & \multicolumn{2}{|l|}{ Material Type } & \multirow[t]{2}{*}{$\begin{array}{l}\text { Density } \\
(\mathrm{kg} / \mathrm{m} 3)\end{array}$} & \multirow[t]{2}{*}{ Mass (kg) } & \multirow[t]{2}{*}{$\begin{array}{l}\text { Embodied } \\
\text { Energy (EE) } \\
\text { Intensity(MJ/kg) }\end{array}$} \\
\hline & & $v$ & & & \\
\hline & & $v$ & & & \\
\hline 15.89 & Timber - Sawn Hardwood & $\nabla$ & 600.00 & 9534 & 10 \\
\hline 5.30 & Timber - Sawn Hardwood & $\checkmark$ & 600.00 & 3180 & 10 \\
\hline 0.00 & Bitumen -General & 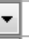 & 8.500 .00 & 0 & 44 \\
\hline \multirow[t]{3}{*}{10.59} & Insulation - Rockwool & F & 23.00 & 243.57 & 16.8 \\
\hline & & 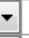 & & & \\
\hline & & - & & & \\
\hline 4.03 & Clay - Tile & 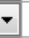 & 1.900 .00 & 7657 & 6.5 \\
\hline \multirow[t]{2}{*}{1.32} & General - Insulation & 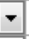 & 140.00 & 184.8 & 45 \\
\hline & & 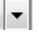 & & & \\
\hline
\end{tabular}

Embodied
Cabon (EC) \begin{tabular}{|l|l|l|l|l|l|}
\begin{tabular}{|l|l|l|} 
Embodied \\
Energy (G)
\end{tabular} & $\begin{array}{l}\text { Embodied } \\
\text { Carbon ACO2) }\end{array}$ & $\begin{array}{l}\text { Work } \\
\text { Breakdown } \\
\text { EE (MJ) }\end{array}$ & $\begin{array}{l}\text { Work } \\
\text { Breakdown } \\
\text { EC (ACO2) }\end{array}$ & $\begin{array}{l}\text { Unit cost } \\
\text { (f) }\end{array}$ & $\begin{array}{l}\text { Amount } \\
(\mathrm{f})\end{array}$ \\
\hline
\end{tabular}

Fig. 15. Roof item entries

736

\begin{tabular}{|c|c|c|c|}
\hline \multicolumn{4}{|c|}{ Group items details } \\
\hline & Number & Work Breakdown Stucture (WBS) - them & $\begin{array}{l}\text { Volume } \\
(\mathrm{m} 3)\end{array}$ \\
\hline 199 & 2.5 .1 .9 & Extra Over Projecting Fins for Applied Atwork & \\
\hline 200 & 2.5 .2 & Extemal Enclosing Ground Level & \\
\hline 201 & 2.5 .2 .1 & Bick or Block Walls & 10.55 \\
\hline 202 & 2.5.2.2 & Motter for Joints & \\
\hline 203 & 2.5 .2 .3 & Wall flexible insulation & 7.72 \\
\hline 204 & 2.5.2.4 & Wall rigid and semi-igid insulation & 1.29 \\
\hline 205 & 2.5 .2 .5 & Wall Concrete Units & 10.29 \\
\hline
\end{tabular}

738

Fig. 16. External walls 
741 The quantities extracted from the external walls are presented in Figure 16. Similarly, all the components of the external walls were manually computed using the model in Revit or Figure 9, and the results were not significantly different from the one pulled from the Revit model.

744 For example, the manual computation of the brick or block walls can be obtained using the 745 formula 6.

$746 \quad$ Volume $=$ Perimeter*Thickness $*$ Height $=(7.5 * 2+11.5+4 * 2+2.48 * 2+0.4525 * 2+1.27 * 2+0.395 * 2) * 0.1025 * 2.6 \mathrm{~m}^{3}$ $=11.64 \mathrm{~m}^{3}$

The computed volume is $11.64 \mathrm{~m}^{3}$ compared to $10.55 \mathrm{~m}^{3}$, which is not significant. For internal walls, the same procedure has been applied and results presented in Figure 17. For the internal walls, the height is $2.6 \mathrm{~m}$, the thickness of insulation is $12.5 \mathrm{~mm}$ and perimeter is $35 \mathrm{~m}$. By using Equation 6, the volume of the insulation can be computed as:

Volume $=35 * 0.0125 * 2.6 \mathrm{~m}^{3}$$$
=1.14 \mathrm{~m}^{3}
$$

The results from the manual computation of the insulation is not significantly different from the $1.13 \mathrm{~m}^{3}$ pulled from the BIM model using our system.

To determine the accuracy of the volumes extracted by the system from the Revit model, we computed and compared the standard errors from the extracted volumes to those computed from manual measurements. For the case of the extracted volumes, the number of data $n$ corresponding to the number of building components is 58 and the mean and standard deviation are $4.5 \mathrm{~m}^{3}$ and $6.42 \mathrm{~m}^{3}$ respectively. Using these values the standard error is computed by dividing the standard deviation by the square root of $n=58$. Thus the standard error obtained is $0.84 \mathrm{~m}^{3}$. Similarly for the manual computed volumes from the model, the mean and standard deviation were $4.3 \mathrm{~m}^{3}$ and $6.8 \mathrm{~m}^{3}$ for the same data sample of 58 . Using these values the standard error was $0.89 \mathrm{~m}^{3}$. The two standard errors are significantly closed.

768 Lower or smaller standard errors indicate the more precise estimates or accuracy of the extracted values. 


\begin{tabular}{|c|c|c|c|c|c|c|c|c|c|c|}
\hline \multicolumn{11}{|c|}{ Group items details } \\
\hline & Number & Work Breakdown Stucture (WBS) - ttem & Volume (m3) & Material Type & $\begin{array}{l}\text { Density } \\
(\mathrm{kg} / \mathrm{m} 3)\end{array}$ & $\begin{array}{l}\text { Mass } \\
(\mathrm{kg})\end{array}$ & $\begin{array}{l}\text { Embodied Energy (EE) } \\
\text { Intensity(MJ/kg) }\end{array}$ & $\begin{array}{l}\text { Embodied Carbon (EC) } \\
\text { Intensity }(\mathrm{kgCO} 2 / \mathrm{kg})\end{array}$ & $\begin{array}{l}\text { Embodied } \\
\text { Energy (GJ) }\end{array}$ & $\begin{array}{l}\text { Embodied } \\
\text { Carbon (tCO2) }\end{array}$ \\
\hline 252 & 2.7 & Intemal Walls and Partitions & & & & & & & & \\
\hline 253 & 2.7 .1 & Walls and Partitions & & & . & & & & & \\
\hline 254 & 2.7.1.1 & Intemal Walls - Partitions Brick or block units & & & . & & & & & \\
\hline 255 & 2.7.1.2 & Morter for Joints & & & . & & & & & \\
\hline 256 & 2.7 .1 .3 & Wall flexible insulation & & & 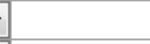 & & & & & \\
\hline \multirow{3}{*}{$\begin{array}{r}25 \\
258 \\
259\end{array}$} & 2.7 .1 .4 & Wall rigid and semi-rigid insulation & 1.13 & Insulation - Woodwool (Board) & 160.00 & 180.8 & 20 & 0.98 & 3.616 & 0.177184 \\
\hline & 2.7.1.5 & Wall Concrete Units & & & . & & & & & \\
\hline & 2.7.1.6 & Wall Metal studs related layers & 3.18 & Steel - General - World Avg. R... & $7,850.00$ & 24963 & 45.4 & 3.05 & 1133.3202 & 76.13715 \\
\hline
\end{tabular}

Fig. 17: Internal walls 


\section{Challenges and future research}

\subsection{Quantity of plasterboard of internal walls and external walls being mixed if they are} made of the same material type.

In extracting the quantities from the Revit model, the system summed the volumes of similar objects belonging to different components. For example, the type of plasterboard chosen for the internal wall and external wall were the same with name Gypsum plaster board. When the quantities are extracted for walls, the volumes for the Gypsum plasterboard are summed and presented as if the plasterboard belongs to only one of the components. This is wrong as the different volumes should appear under external wall and internal walls. To overcome this challenge, two solutions are proposed. The first is to rename the different Gypsum boards differently in the model before importing, for example, Gypsum board (for internal) and Gypsum board_ext. The second solution is to choose different material types of the Gypsum board for the internal and external walls. We tried both methods and they worked, although we adopted the first option in this study as can be seen on the right of Figure 18.

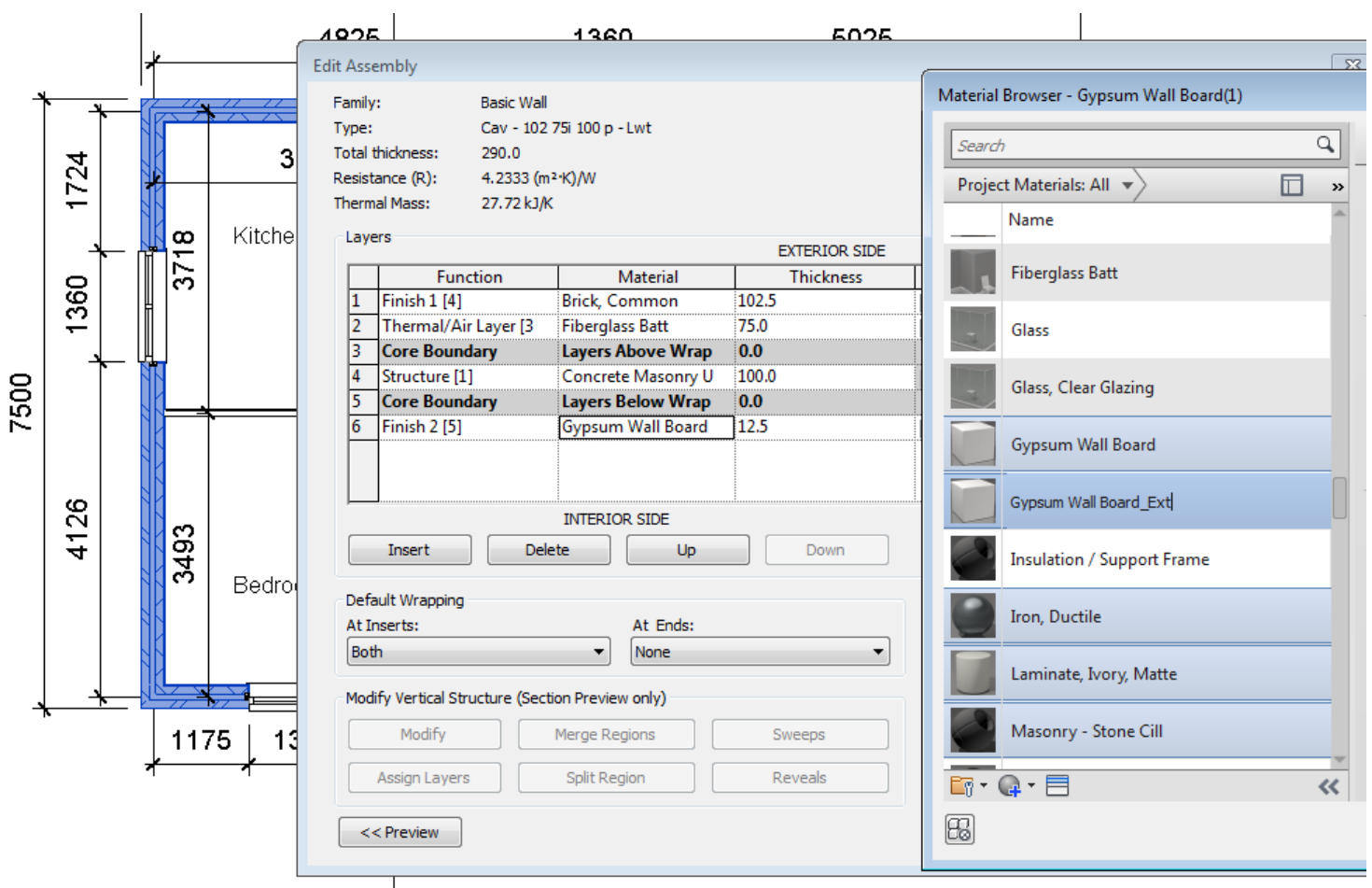

Fig. 18. Changing the name of type of insulation before exporting to the proposed system 


\subsection{Structure of Bath ICE data}

The Bath ICE database contains information for numerous numbers of materials used in construction. However, a few of the material entries have incomplete information. For example, Felt General, listed under the miscellaneous group of materials has no entry for embodied carbon intensity value. As such, a close substitute (Bitumen General) was used. Also, there are some material embodied energy and carbon intensity values that were entered as range (e.g. Rubber) or with question mark (e.g. Damp Proof Course/Membrane) indicating level uncertainty. In the case of range entry, the maximum values were used and the question mark was ignored in the latter case. In addition, the densities of some materials such as Paint and Sealants \& Adhesives were not found in the database. Lastly, the structure of the database was not suitable to be used directly. Hence; the structure of information in the Bath

810 ICE material information spreadsheet had to be altered to be able convert them to committable SQL database entries.

812

\subsection{Different measurement units}

814 The computation of embodied energy and $\mathrm{CO}_{2}$ are based on intensities expressed in the Bath

815 ICE. The intensities in the inventory are expressed in units $/ \mathrm{kg}$ or units $/ \mathrm{kgCO}_{2}$. Hence,

816 quantities were extracted from Revit in volumes which can be converted to mass in $\mathrm{kg}$. This

817 means, the system can only be used to compute corresponding cost of components that the

818 unit cost is expressed as per volume (see the volume and unit cost columns of Figure 10,

819 Section 6.3). However, in practice cost have different units including $\mathrm{m}^{2}$, linear metres (m)

820 and lump sum and this will require to be modelled differently. We anticipate addressing this

821 issue as part of another study.

822

\section{$823 \quad$ 8.4 Impossibility in simultaneously working with Revit and the proposed tool}

824 The proposed tool is hosted on Revit platform as an add-in. As such, once an end-user is working with the proposed tool, Revit needs to be running in the background. At the moment

826 it is not possible to work on Revit simultaneously while the proposed tool is running. It may

827 become possible to achieve this with future expansion of the proposed system. 


\section{Discussions}

830 In this study, a total of seven houses with known information were modelled in Revit and 831 quantities extracted automatically and fed into the required volume placeholders in the 832 proposed system. The placeholders consist of concepts based on NRM 1. The automatic 833 insertion of QTO into a structured NRM 1 is a major solution to a problem that has plagued 834 professionals since the popularisation of BIM (Olatunji et al. 2010; Monteiro and Martins, 835 2013; Wu et al., 2014). As a reminder, the major problem is the disorderly nature of QTO 836 outputs from BIM authoring tools such as Revit and their non-alignment with standard measurement methods. Cognisance of this, the Royal Institution of Chartered Surveyors, one of the global leading chartered surveyor's institute funded a study to investigate how BIM can support the UK NRM (NRM 1) (Wu et al., 2014). The outcome of this study was theoretical and one of the main recommendations was the need of an automated system for generating quantities and alignment to NRM. As an application, once the quantities have been automatically extracted and inserted into the NRM 1, the system then computes embodied energy and $\mathrm{CO}_{2}$ are computed in an automatic fashion while aligning the results to the NRM 1. The major contributions of this study include the process model integrated BIMbased framework for the automatic computation of embodied energy/ $/ \mathrm{CO}_{2}$ and cost (see Figure 1) and the algorithmic process model for assessment of embodied energy and $\mathrm{CO}_{2}$ (see Figure 3). Other contributions that emerged from implementing the stated process models (see Figures 1 and 3) include:

- an algorithm for extracting material quantities, computing embodied energy/ $/ \mathrm{CO}_{2}$ and cost and aligning results to a NRM 1 in a BIM environment;

- a program that builds on the aforementioned algorithm for the automatic extraction of

854 Fitting/aligning the quantities and hence embodied energy and $\mathrm{CO}_{2}$ computational results in New Rules of Measurement concepts makes it easy to compare and align cost items of the various work breakdown structure.

- a system that integrates the process of assessment of embodied energy/ $/ \mathrm{CO}_{2}$ and cost, which allows the simultaneous determination of environmental impacts of different building components and/or work break down structure together with its associated cost. 
862 However, there were some challenges experienced during the undertaking of this study. This 863 has been covered in detail in section 8 . However, the limitation related to cost, embodied 864 energy $/ \mathrm{CO}_{2}$ units will be discussed. The units of measurement for cost of building material in 865 the proposed system is linked to volume (i.e. $£ / \mathrm{m}^{3}$ ). Similarly, the units of embodied energy 866 and $\mathrm{CO}_{2}$ edited in the proposed system were $\mathrm{MJ} / \mathrm{Kg}$ and $\mathrm{Kg} / \mathrm{KgCO}$ respectively. This was 867 because we chose to use the Bath ICE that is constrained by these units. However, the units 868 of measurements of material quantities can be in linear metres, $\mathrm{m}^{2}$ and lump sum. Also, it is 869 possible to have units of embodied energy to be in $\mathrm{MJ} / \mathrm{m}^{2}$ (Fridley et al., 2008). For now, it is 870 not possible to deal with two different units in one column in the proposed system. As part of 871 our future study we will investigate how the complete cost components can be further 872 developed to deal with measurement units such as linear metres, $\mathrm{m}^{2}$ and lump sum. Also, an 873 investigation will be conducted to determine how embodied energy and $\mathrm{CO} 2$ can be 874 computed in different units while aligning the results with NRM 1.

\section{Conclusions}

877 The overall aim of this study was to develop and test a system that automate the computation 878 of embodied energy and $\mathrm{CO}_{2}$ of houses and align the results to existing UK standard rules of measurement (NRM). In order to achieve this aim, a thorough literature review was

880 undertaken which led to identification of knowledge gaps about the domain. Specifically, it 881 emerged that most mathematical models for embodied energy and $\mathrm{CO}_{2}$ computations exist in 882 isolation. This work explored and adapted existing computational models based on matrices proposed in the British Standards (BS 2010) to develop a system generalised computation models for embodied energy and $\mathrm{CO}_{2}$. Models developed by BS (2010) were chosen because they were more encompassing than most existing models. Secondly, the NRM is text-book based, so it was necessary to develop an electronic version that can be automatically called/edited into the proposed system such that the computational results of embodied energy and $\mathrm{CO}_{2}$ can easily be aligned to it. We opted to re-use an existing ontology from the works developed by Abanda et al. (2015).

891 The NRM ontology was mapped to XML codes which loaded in Navisworks and exported to 892 spreadsheet for ease of importation into the proposed system. The system is interfaced with 893 Revit, one of the most popular BIM tool in the construction industry. This means a model 894 needs to be created in Revit and the Revit system has to be left running for the system to 
895

896

897

898

899

900

901

902

903

904

905

906

907

908

909

910

911

912

913

914

915

916

917

918

919

920

921

922

923

924

925

926

work. While Revit is running, the user cannot work on both simultaneously. Once the system is launched the interface is populated with NRM 1. The model in Revit is called in and the building components and quantities or volumes are automatically brought into the system and aligns or maps with the concepts or work-break down structure of NRM 1. The system then uses an in-built density, embodied energy and $\mathrm{CO}_{2}$ intensities database restructured or adapted from the Bath ICE to computed quantities in $\mathrm{kg}$, and hence embodied energy and $\mathrm{CO}_{2}$ respectively. The total for each work break down structure can be obtained. Also the columns for unit cost and amount in $£$ were included to enable comparison of environmental impact of work break-down structure with corresponding cost. This can clearly guide decision makers not to base their decisions only on cost but also to consider environmental impacts. Knowing the environmental impacts of given house components and hence total for work break down structure can guide end users to change the material type in the Revit model so as to achieve a minimum level of environmental impacts of the whole building.

\section{References}

Abanda F.H., Kamsu-Foguem B. and Tah J.H.M. (2015) Towards an intelligent ontology construction cost estimation system: Using BIM and New Rules of Measurement techniques. International Journal of Computer, Control, Quantum and Information Engineering, Vol. 9 (1), pp. 294-299.

Abanda F.H.,Nkeng G.E.,Tah J.H.M., Ohandja E.N.F. and Manjia M. B. (2014) Embodied energy and $\mathrm{CO}_{2}$ analyses of mud-brick and cement-block houses. AIMS Energy, Vol. 2 (1), pp.18-40.

Abanda F.H., Tah J.H.M and Cheung F.K.T. (2013a) Mathematical modelling of embodied energy, greenhouse gases, waste, time-cost parameters of building projects. Building and Environment, Vol. 59, pp.23-37.

Abanda F. H., Tah, J. H. M. and Keivani, R. (2013b) Trends in built environment Semantic Web applications: Where are we today? Expert Systems With Applications, Vol. 40 (14), pp. 5563-5577.

Abanda H., Tah J.H.M., Cheung F. and Zhou W. (2010) Measuring the embodied energy, waste and $\mathrm{CO}_{2}$ emissions from construction activity: An overview. In: The Proceedings of the International Conference on Computing in Civil and Building Engineering 2010, June 30-July 2, The University of Nottingham, UK, pp. 361-366. 
ADEME (2017). Climate change: the urgent need for an inventory. [Online] http://www2.ademe.fr/servlet/KBaseShow? sort $=-1 \&$ cid $=23674 \& m=3 \&$ catid $=23675$ [Access June 2017].

Atmaca A. and Atmaca N. (2015) Life cycle energy (LCEA) and carbon dioxide emissions (LCCO2A) assessment of two residential buildings in Gaziantep, Turkey. Energy and Buildings, Vol. 102, pp. 417-431.

Bazjanac V. (2001) Acquisition of building geometry in the simulation of energy performance. Seventh International IBPSA Conference Rio de Janeiro, Brazil, August 13$15,2001$.

BIS (2010) Estimating the amount of $\mathrm{CO}_{2}$ emissions that the construction industry can influence - supporting material for the Low Carbon Construction IGT Report, 2010, Available: https://www.gov.uk/government/uploads/system/uploads/attachment data/file/31737/10-1316-estimating-co2-emissions-supporting-low-carbon-igt-report.pdf BS (2010) BS EN 15643-1:2010-Sustainability of construction works - Sustainability assessment of buildings Part 1: General framework. British Standards, UK.

Bullard, C. W., Penner, P. S. and Pilati, D. A. (1978) Net energy analysis--handbook for combining process and input-output analysis. Resources and Energy, 1, pp. 267-313.

Cabeza L.F., Barreneche C., Miró L., Morera J.M., Bartolí E and Fernández A.I. (2013) Low carbon and low embodied energy materials in buildings: A review. Renewable and Sustainable Energy Reviews, Vol. 23, pp. 536-542.

Cabeza LF, Rincón L, Vilariño V, Pérez G and Castell A (2014) Life cycle assessment (LCA) and life cycle energy analysis (LCEA) of buildings and the building sector: A review. Renewable and Sustainable Energy Reviews, Vol. 29, pp. 394-416.

Chang Y, Ries RJ and Wang Y. (2010) The embodied energy and environmental emissions of construction projects in China: An economic input-output LCA model. Energy Policy, Vol. 38, pp. 6597-6603.

Davies P.J., Emmitt S. and Firth S.K. (2015) Delivering improved initial embodied energy efficiency during construction. Sustainable Cities and Society, Vol. 14, pp. 267-279.

Crawford R.H. and Treloar G.J. (2003) Validation of the use of Australian input output data for building embodied energy simulation. In: Eighth International IBPSA Conference, Eindhoven, Netherlands, 2003. [Online] http://www.inive.org/members area/medias/pdf/Inive\%5CIBPSA\%5CUFSC881.pdf [Accessed January 2016]. 
960 Ding G.K.C. (2004) The development of a multi-criteria approach for the measurement of 961 sustainable performance for built projects and facilities, Ph.D. Thesis, University of 962 technology, Sydney, Australia, 2004. [Online]

963 https://opus.lib.uts.edu.au/bitstream/10453/20191/7/02Whole.pdf [Accessed January 964 2016].

965 Dixit M K, Fernandez-Solis J L, Lavy S, Culp C H (2010) Identification of parameters for 966 embodied energy measurement: A literature review. Energy and Buildings, 42, 1238-1247.

967 Dixit M K, Fernandez-Solis J L, Lavy S, Culp C H (2012) Need for an embodied energy 968 measurement protocol for buildings: A review paper. Renewable and Sustainable Energy 969 Reviews, 16, 3730-3743.

ECO (2017). The Ecoinvent Database. [Online] http://www.ecoinvent.org/database/ [Accessed June 2017].

EFDB (2017). Welcome to EFDB! [Online] http://www.ipccnggip.iges.or.jp/EFDB/main.php [Accessed June 2017].

Fridley D.G., Zheng N. and Zhou N. (2008) Estimating total energy consumption and emissions of China's commercial and office buildings. This work was supported by the Environmental Protection Agency, Office of Atmospheric Programs through the U.S. Department of Energy under Contract No. DEAC02-05CH11231. [Online]

https://china.lbl.gov/sites/all/files/lbl-248e-commercial-buildingmarch-2008.pdf [Accessed January 2017].

GaBi(2017) LCA Databases. [Online] http://www.gabi-software.com/uk-ireland/databases/ [Accessed June 2017].

Galán-Marín C., Rivera-Gómez C. and García-Martínez A. (2015) Embodied energy of conventional load-bearing walls versus natural stabilized earth blocks. Energy and Buildings, Vol. 97, pp. 146-154.

986

Gaspar P.L. and Santos A.L. (2015) Embodied energy on refurbishment vs. demolition: A southern Europe case study. Energy and Buildings, Vol. 87, pp. 386-394.

Gertsev VI and Gertseva VV. (2004) Classification of mathematical models in ecology.

989 Gómez-Pérez A., Fernández-López M. and Corcho O. (2011) Ontological engineering with 990 examples from the areas of knowledge management, e-Commerce and the Semantic Web. 991 Springer-Verlag London Limited, UK.

992 González M J and Navarro J G (2006) Assessment of the decrease of $\mathrm{CO}_{2}$ emissions in the 993 construction field through the selection of materials: Practical case study of three houses 994 of low environmental impact. Building and Environment, Vol. 41 (7), 902-909. 
995

996

997

998

999

1000

1001

1002

1003

1004

1005

1006

1007

1008

1009

1010

1011

1012

1013

1014

1015

1016

1017

1018

1019

1020

1021

1022

1023

1024

1025

1026

1027

1028

Grzybek H., Xu S., Gulliver S. and Fillingham V. (2014). "Considering the feasibility of semantic model design in the Built-Environment.” Buildings, Vol. 4, pp. 849-879.

Häkkinen T., Kuittinen M. , Ruuska A , Jung N. (2015) Reducing embodied carbon during the design process of buildings. Journal of Building Engineering, Vol. 4, pp.1-13.

Hammond G.P. and Jones C.I. (2008). Embodied energy and carbon in construction materials, Proceedings of the ICE - Energy, Vol. 161 (2), pp. 87-98.

Hersh M. (2006) Mathematical modeling for sustainable development. New York: Springer.

Hou S., Li H. and Rezgui Y. (2015) Ontology-based approach for structural design considering low embodied energy and carbon. Energy and Buildings, Vol. 102, pp. 75-90.

HM Government (2011) The Carbon Plan: Delivering our Low Carbon Future (2011) [Online]

https://www.gov.uk/government/uploads/system/uploads/attachment_data/file/47613/3702 -the-carbon-plan-delivering-our-low-carbon-future.pdf [accessed 08.08.2015].

HMSO (2008) Climate Change Act 2008, HMSO, London.

Ilhan B. and Yaman H. (2016) Green building assessment tool (GBAT) for integrated BIMbased design decisions. Automation in Construction, in press, doi:10.1016/j.autcon.2016.05.001

Jang M., Hong T. and Ji C. (2015) Hybrid LCA model for assessing the embodied environmental impacts of buildings in South Korea. Environmental Impact Assessment Review, Vol. 50, pp. 143-155.

Kibwami, N and Tutesigensi, A (2014) Mathematical modelling of embodied carbon emissions of building projects In: Raiden, A B and Aboagye-Nimo, E (Eds) Procs 30th Annual ARCOM Conference, 1-3 September 2014, Portsmouth, UK, Association of Researchers in Construction Management, 53-62.

Kim H.and Anderson K. (2013) Energy modelling system using Building Information Modeling Open Standards. Journal of Computing in Civil Engineering, Vol. 27 (3), pp. 203-211.

Kundzewicz Z.W., Afouda A. and Szolgay J. (2000) Mathematical modelling. Journal of Hydrology 2000:171.

Lave L.B., Cobas-Flores E., Hendrickson C.T. and McMichael. F. (1995). Life cycle assessment: using input output analysis to estimate economy-wide discharges. Environmental Science and Technology, 29, 420A-6A.

Lenzen, M., (2001) Errors in conventional and input-output-based lifecycle inventories. Journal of Industrial Ecology 4 (4), 127-148. 
Lenzen, M., (2002) A guide for compiling inventories in hybrid life-cycle assessment: some Australian results. Journal of Cleaner Production . 10, 545-572.

1031 Leontief W. (1966) Input-output economics. New York, NY, USA: Oxford University Press.

1032 Leontief W. (1970) Environmental repercussions and the economic structure: An input-

1033 output approach. Review of Economics and Statistics, Vol. 52(3), pp. 262-271.

1034 Ma Z., Wei Z. and Zhang X. (2013) Semi-automatic and specification-compliant cost

1035 estimation for tendering of building projects based on IFC data of design model.

1036 Automation in Construction, Vol. 30, pp. 126-35.

1037

Monteiro A. and Martins J.P. (2013) A survey on modeling guidelines for quantity takeofforiented BIM-based design. Automation in Construction, Vol. 35, pp. 238-253

Nepal M.P., Staub-French S., Pottinger R. and Zhang J. (2013) Ontology-based feature modelling construction information extraction from a building information model. Journal of Computing in Civil Engineering, Vol. 27(5), pp. 555-569

Neuberg F. and Rank E. (2002) Internet based simulation of the resource requirement of buildings. eWork and eBusiness in Architecture, Engineering and Construction, Turk and Scherer (eds), A.A. Balkema, The Netherlands.

Noy N.F. and Mcguinness D.L (2001) Ontology development 101: A guide to creating your first ontology. Knowledge System Laboratory, Stanford, CA.

Oka, T., Suzuki, M. and Konnya, T. (1993) The estimation of energy consumption and amount of pollutants due to the construction of buildings, Energy and Buildings, 9, pp. 303-311.

Olatunji, O. A., Sher W. D. and Gu N. (2010) Building Information Modelling and Quantity Surveying Practice - Whatever you though, think again. Emirates Journal for Engineering Research, Vol. 15 (1), pp. 67-70.

Olatunji O.A. and Sher W. (2014) Perspectives on modelling BIM-enabled estimating practices. Australasian Journal of Construction Economics and Building, Vol. 14(4), pp. $32-53$.

Oti, A. H. and Tizani, W. (2015). BIM extension for the sustainability appraisal of conceptual steel design. Advanced Engineering Informatics, Vol. 29(1), pp. 28-46.

Pacheco-Torgal F, Faria J and Jalali S (2013) Embodied energy versus operational energy. Showing the shortcomings of the Energy Performance Building Directive (EPBD). Materials Science Forum, Vol. 730-732, 587-591.

Pauwels P., Zhang S. and Lee Y.-C. (2016) Semantic web technologies in AEC industry: A literature overview. Automation in Construction (in press) 
1063 Rauf A. and Crawford R.H. (2015) Building service life and its effect on the life cycle embodied energy of buildings. Energy, Vol. 79, pp. 140-148.

RICS (2012) RICS New Rules of Measurement: Detailed measurement for building works. Royal Institution of Chartered Surveyors, UK.

RICS (2009) RICS New Rules of Measurement: Order of cost estimating and elemental cost planning. Royal Institution of Chartered Surveyors, UK.

Sartori I and Hestnes AG (2007) Energy use in the life cycle of conventional and low-energy buildings: A review article. Energy and Buildings, Vol. 39 (3), pp. 249-257.

.Staub-French S., Fischer M., Kunz J. and Paulson B. (2003) An ontology for relating features with activities to calculate costs. Journal of Computing in Civil Engineering, Vol. 17(4), pp. 243-254.

1074 Sturgis S and Roberts G (2010) Redefining zero: carbon profiling as a solution to whole life carbon emission measurement", London: The Royal Institution of Chartered Surveyors.

Takano A., Winter S., Hughes M. and Linkosalmi L. (2014) Comparison of life cycle assessment databases: A case study on building assessment. Building and Environment, Vol. 79, pp. 20-30.

Thormark C. (2006) The effect of material choice on the total energy need and recyclying potential of a building. Building and Environment, Vol. 41 (8), 1019-1026.

Simmons, C., Stentiford, C., Laorga, R. and Sheane, R. (2010) Carbon footprint study. [Online] http://www.mma.gov.br/estruturas/255/_arquivos/carbon footprint study relat 255.pdf [January 2011].

Suh, S., and Huppes, G., (2002) Missing inventory estimation tool using input-output analysis. International Journal of Life-Cycle Assessment 7 (3), 134-140.

Treloar, G. J. (1994) Embodied energy analysis of the construction office buildings, Master of Architecture Thesis, Deakin University, Geelong.

Treloar, G.J. (1997) Extracting embodied energy paths from input-output tables: towards an input-output-based hybrid energy analysis method. Economic Systems Research 9 (4), 375-391.

Treloar, G.J., Love, P.E.D., and Holt, G.D. (2001) Using national input-output data for embodied energy analysis of individual residential buildings. Construction Management and Economics 19, 49-61. 
1095 Treloar, G.J., Gupta, H. Love, P.E.D. and Nguyen, B. (2003) An analysis of factors 1096 influencing waste minimisation and use of recycled materials for construction of 1097 residential buildings. Management of Environmental Quality: An International Journal, 1098 14(1), pp.134-145.

1099 Vernikos V.K (2012) Optimising Building Information Modelling and off-site construction 1100 for civil engineering. Civil Engineering, Vol. 165 (CE4), pp. 147.

1101 Wu, S., Ginige, K., Wood, G. and Jong, S. (2014) How Can BIM support the New Rules of 1102 Measurement (NRM 1)? London, UK: RICS.

1103 Teng J. and Wu X. (2014) Eco-footprint-based life-cycle eco-efficiency assessment of 1104 building projects. Ecological Indicators, Vol. 39, pp. 160-168.

1105 The HM Government (2013a) Construction 2025: industrial strategy for construction 1106 government and industry in partnership. The HM Government, UK.

1107 Zhang L. and Issa R.R.A. (2013) Ontology-based partial building information model. Journal 1108 of Computing in Civil Engineering, Vol. 27 (6), pp. 576-584.

1109 Zhiliang M., Zhenhua W., Wu, S. and Zhe L. (2011) Application and extension of the IFC 1110 standard in construction cost estimating for tendering in China, Automation in 1111 Construction, Vol. 20 (2), pp. 196-204. 


\section{Appendix}

1115

1116 Table 1. Validation of results

Stanard error

$\begin{array}{lll}\text { Rule of } & \text { Building } & \text { Component } \\ \text { Measurement } & \text { Element } & \text { material } \\ \text { Category } & & \end{array}$

\begin{tabular}{llllllll}
\hline Building 1 & Building 2 & Building 3 & Building 4 & Building 5 & Building 6 & Building 7 & Negligible for each \\
$($ GFA $=84.41$ & $($ GFA $=98.48$ & $($ GFA $=137.03$ & $($ GFA $=187.65$ & $($ GFA $=89.14$ & $($ GFA $=178.72$ & $($ GFA $=$ & building \\
$\left.\mathrm{m}^{2}\right)$ Quantities & $\left.\mathrm{m}^{2}\right)$ Quantities & $\left.\mathrm{m}^{2}\right)$ & $\left.\mathrm{m}^{2}\right)$ & $\left.\mathrm{m}^{2}\right)$ & $\left.\mathrm{m}^{2}\right)$ & $\left.\mathbf{2 6 8 . 2 0} \mathbf{m}^{2}\right)$
\end{tabular}

$\left(\mathbf{m}^{3}\right)$

$\begin{array}{llllll}\left(\mathbf{m}^{3}\right) & \text { Quantities }\left(\mathrm{m}^{3}\right) & \text { Quantities }\left(\mathrm{m}^{3}\right) & \text { Quantities }\left(\mathrm{m}^{3}\right) & \text { Quantities }\left(\mathrm{m}^{3}\right) & \text { Qu }\end{array}$

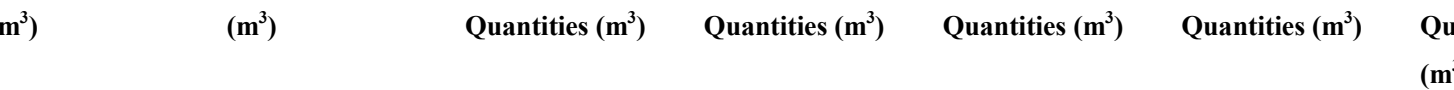

$\left.\mathbf{m}^{2}\right)$

$268.20 \mathrm{~m}^{2}$ )

\begin{tabular}{|c|c|c|c|c|c|c|c|c|c|c|}
\hline $\begin{array}{l}\text { Standard } \\
\text { Foundation }\end{array}$ & $\begin{array}{l}\text { Concrete: Cast } \\
\text { In Situ }\end{array}$ & $\begin{array}{l}\text { Concrete: Cast } \\
\text { In Situ }\end{array}$ & 12.4 & 11.73 & 13.35 & 40.06 & 12.43 & 12.43 & 12.43 & $\begin{array}{l}\text { Negligible for each } \\
\text { building }\end{array}$ \\
\hline \multirow{2}{*}{ Upper Floors } & \multirow[t]{2}{*}{ Floor } & $\begin{array}{l}\text { Wood Sheathing: } \\
\text { Chipboard }\end{array}$ & Not applicable & Not applicable & Not applicable & 4.13 & Not applicable & 2.15 & 4.23 & $\begin{array}{l}\text { Negligible for each } \\
\text { building }\end{array}$ \\
\hline & & $\begin{array}{l}\text { Structure: Timber } \\
\text { Joist/Rafter Layer }\end{array}$ & Not applicable & Not applicable & Not applicable & 42.23 & Not applicable & 21.95 & 43.72 & $\begin{array}{l}\text { Negligible for each } \\
\text { building }\end{array}$ \\
\hline $\begin{array}{l}\text { Stairs and } \\
\text { Ramps }\end{array}$ & Stair & Wood & Not applicable & Not applicable & Not applicable & 0.24 & Not applicable & 0.49 & 0.99 & $\begin{array}{l}\text { Negligible for each } \\
\text { building }\end{array}$ \\
\hline \multirow{4}{*}{ External walls } & \multirow[t]{4}{*}{ Wall } & Brick: Common & 10.63 & 9.46 & 21.95 & 22.42 & 11.64 & 22.12 & 32.54 & $\begin{array}{l}\text { Negligible for each } \\
\text { building }\end{array}$ \\
\hline & & $\begin{array}{l}\text { Concrete Masonry } \\
\text { Units }\end{array}$ & 10.38 & 9.23 & 21.46 & 19.88 & 14.46 & 27.24 & 40.1 & $\begin{array}{l}\text { Negligible for each } \\
\text { building }\end{array}$ \\
\hline & & Fiberglass Batt & 7.78 & 6.92 & 16.08 & 15.65 & 8.98 & 17.03 & 25.05 & $\begin{array}{l}\text { Negligible for each } \\
\text { building }\end{array}$ \\
\hline & & Gypsum Wall & 1.30 & 1.15 & 2.68 & 2.41 & 1.61 & 2.7 & 3.97 & Negligible for each \\
\hline
\end{tabular}


Board_Ext

\begin{tabular}{|c|c|c|c|c|c|c|c|c|c|c|}
\hline $\begin{array}{l}\text { Fittings } \\
\text { Furnishes and } \\
\text { Equipment }\end{array}$ & Furniture & Wood-birch & 0.13 & 0.14 & 0.14 & 0.14 & 0.13 & 0.27 & 0.4 & $\begin{array}{l}\text { Negligible for each } \\
\text { building }\end{array}$ \\
\hline $\begin{array}{l}\text { Sanitary } \\
\text { Installations }\end{array}$ & $\begin{array}{l}\text { Plumbing } \\
\text { Fixtures }\end{array}$ & $\begin{array}{l}\text { Bath tub /WC - } \\
\text { Porcelain }\end{array}$ & 0.30 & 0.62 & 0.59 & 0.95 & 0.30 & 0.62 & 0.98 & $\begin{array}{l}\text { Negligible for each } \\
\text { building }\end{array}$ \\
\hline Heaters & $\begin{array}{l}\text { Mechanical } \\
\text { Equipment }\end{array}$ & $\begin{array}{l}\text { Steel - Chrome } \\
\text { plated }\end{array}$ & 0.07 & 0.09 & 0.09 & 0.09 & 0.07 & 0.12 & 0.18 & $\begin{array}{l}\text { Negligible for each } \\
\text { building }\end{array}$ \\
\hline \multicolumn{3}{|c|}{$\begin{array}{l}\text { System extract quantities from all the different NRM } 1 \\
\text { concepts (Yes or No) }\end{array}$} & Yes & Yes & Yes & Yes & Yes & Yes & Yes & \\
\hline \multicolumn{3}{|c|}{$\begin{array}{l}\text { Any mixed up in the extraction and insertion of } \\
\text { quantities? (Yes or No) }\end{array}$} & $\begin{array}{l}\text { Initia } \\
\text { code } \\
\text { and } n \\
\text { exper }\end{array}$ & No & No & No & No & No & No & \\
\hline
\end{tabular}

1117 
1118

1119

1120

1121

1122

1123 